\title{
Diagnostics and Intervention in Developmental Dyscalculia: Current Issues and Novel Perspectives
}

\author{
Korbinian Moeller, Ph.D., Ursula Fischer, Mag., Ulrike Cress, Ph.D., \\ and Hans-Christoph Nuerk, Ph.D.
}

\section{Introduction}

When trying to explain developmental dyscalculia, a probable and reasonable way may be to specify it as a developmental learning disorder comparable to developmental dyslexia. The major difference is that dyscalculia does not manifest itself in an impaired processing of written words or text, but of numbers and arithmetic. While noticeably profiting from the fact that most people already know - or at least believe to know - what developmental dyslexia stands for, it is still discouraging to find that knowledge about developmental dyscalculia is much less established. Interestingly, this does not hold for public advertence by parents, teacher, and educational authorities only, but also for research interest dedicated to the issue. A convenient example for the severity of the difference in these two learning disorders' popularity is to compare the hits the two produce in online search engines. We entered the search terms dyslexia and dyscalculia into the search engine Web of Knowledge, on November 3rd, 2010. Our searches yielded a total of 10,880 hits for dyslexia, but only 599 hits for dyscalculia (see Fig. 1 for a comparison of the increase in publications on the two topics over the last 20 years).

These results impressively demonstrate how little dyscalculia has thus far been researched in comparison to its famous counterpart dyslexia. Ever since the first attempts at defining its symptoms (U.S. Office of Education 1977), dyslexia has

K. Moeller, Ph.D. ( $ه)$

Knowledge Media Research Center, Schleichstraße 6, Tüebingen 72076, Germany

Department of Psychology, Eberhard-Karls University, Schleichstraße 4,

Tüebingen 72076, Germany

e-mail: k.moeller@iwm-kmrc.de

U. Fischer, Mag. • U. Cress, Ph.D.

Knowledge Media Research Center, Schleichstraße 6, Tüebingen 72076, Germany

H.-C. Nuerk, Ph.D.

Department of Psychology, Eberhard Karls University Tuebingen Section Diagnostics und

Cognitive Neuropsychology, Schleichstraße 4, Tüebingen 72076, Germany 
Fig. 1 Overview of the number of publications in the last 20 years as found on the ISI Web of Knowledge for entering the topics

'Dyscalculia' and 'Dyslexia'. Please note that for reasons of readability a 5 -year interval has been chosen which perfectly reflects the overall trend

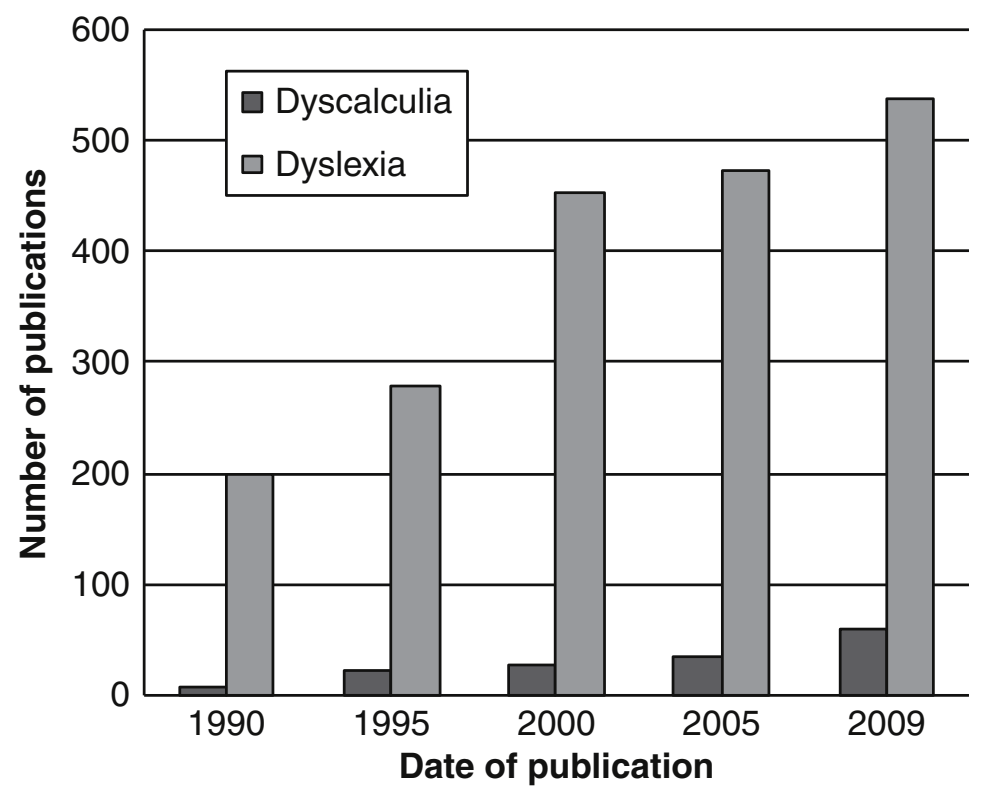

been profusely researched, diagnostic instruments and intervention programmes have been developed, and children with dyslexia are conceded extraordinary assessment regulations in schools in many countries. These regulations may consist of being granted more time for the completion of written tests, the possibility to take exams orally instead of in written form, or the grading of written tests without consideration of spelling errors (even in language classes). So far, no such systematic international regulations have been implemented for children with dyscalculia whose impairments in several areas of academic achievement may be just as severe as those of children with dyslexia. In fact, poor numeracy was found to be even more detrimental to an individual's job opportunities and promotion than poor literacy (Bynner and Parsons 1997; Parsons and Bynner 2005) and a major cost for nations (Gross 2009).

Quite a few possible reasons have been proposed as to why dyscalculia was discovered and accepted as a learning disability much later than dyslexia. One reason might be that the investigation of its neural substrates took longer and was more complex. Another possible explanation may be that the large number of different processes involved in mastery of mathematics complicated a diagnostic definition and a consensus about the aetiology of dyscalculia. There is also the possibility that measures of intelligence had a part in the later discovery, since many of them contain subtests that require arithmetic knowledge and might thereby have lead to a judgment of dyscalculic children as altogether less intelligent. Such a misinterpretation seems comprehensible when taking into account that Thurstone (1938) considered number facility to be one of his seven primary mental abilities. And even today, most of the broadly used intelligence tests incorporate subtests assessing numerical capabilities [e.g., WAIS-IV (Wechsler 2008) and IST 2000-R (Amthauer et al. 2001) for adults and K-ABC (Kaufman and Kaufman 1983) and WISC-IV (Wechsler 2003) for children].

So, we need to discuss why dyscalculia has been studied less. What is certain, however, is that due to this delay, the investigation and treatment development of dyscalculia is still in its infancy. Encouragingly, due to the growing attention 
mathematical learning disabilities receive in research as well as clinical settings our knowledge is accumulating. While the term dyscalculia is still a foreign word to many, it is beside other reasons the high prevalence that has lead to severe growth in its publicity over recent years. It seems as though finally, the failure of certain children to reach age-adequate proficiency in mathematics is no longer being attributed to a lack in motivation or intelligence, but is recognized as a distinct learning disability that needs to be diagnosed and treated accordingly.

Fortunately, developmental dyscalculia attracts more and more attention of researchers, but also parents, teachers, and educational authorities. Against this background, the present chapter discusses four basic but nevertheless very important aspects regarding this developmental disorder: First, we will describe and evaluate the ongoing debate about the origins and causes of developmental dyscalculia. After having illustrated current theoretical accounts, we will then in a second section elaborate on whether and if so, how the diagnostics of dyscalculia should consider different conceptualizations regarding its underlying deficits. Third, the case of comorbidity between developmental dyscalculia and other developmental disorders such as dyslexia will be addressed. In particular, we will recapitulate the issue of estimating comorbidity rates from empirical data and thus helping to evaluate whether observed comorbidity rates are disproportionally higher than expected by chance. Finally, we will briefly review recent remediation programmes for dyscalculia and suggest criteria that such programmes should fulfill to be effective.

\section{Theoretical Underpinnings of Developmental Dyscalculia}

\subsection{The Core Deficit Hypothesis}

Generally, neuroscientific research investigating developmental dyscalculia is still in its infancy and our current understanding of developmental dyscalculia - and thus our diagnostic and treatment methods (see below) - is very limited. Nevertheless, neurocognitive research suggests developmental dyscalculia to be a brain-based disorder. The syndrome-defining cognitive impairment (i.e., deficient numerical capabilities) is supposedly linked to neural abnormality of brain regions in and around the intraparietal sulcus (IPS; Butterworth 2005). Furthermore, there is accumulating evidence for IPS anomalies being associated with numerical deficits on both the structural (i.e., Isaacs et al. 2001; Molko et al. 2003; Rotzer et al. 2008; Rykhlevskaia et al. 2009) and the functional level (i.e., neural activation pattern; developmental dyscalculia in children: Kaufmann et al. 2009b; Kucian et al. 2008; Mussolin et al. 2010a; Price et al. 2007; dyscalculia in adults: Cohen Kadosh et al. 2007). The IPS is generally agreed to be a key structure when it comes to the processing of numerical and in particular number magnitude information (e.g., Pinel et al. 1999; see Dehaene et al. 2003 and Hubbard et al. 2005 for reviews). Thus, recent neuro-imaging data corroborates the notion of developmental dyscalculia 
being caused by deficient processing of very basic numerical concepts such as quantity, magnitude, numerosity, etc. associated with the IPS. This explanatory approach is usually referred to as the core deficit hypothesis of developmental dyscalculia (e.g., Gersten and Chard 1999; Robinson et al. 2002). Therein, it is proposed that all numerical deficits observed in developmental dyscalculia are caused by this central deficit in the processing of number magnitude information, also termed a deficient number module (Butterworth 1999, 2005; Landerl et al. 2004) or a deficient number sense (Dehaene 1997; Wilson et al. 2006a).

However, the existent developmental literature on developmental dyscalculia is inconclusive and inconsistent as regards evidence corroborating the core deficit hypothesis. In line with the hypothesis of a deficient number sense, Mussolin et al. (2010b; see also Landerl and Kölle 2009) observed children with dyscalculia to be impaired in the processing of symbolic but also non-symbolic quantities. However, there is also evidence suggesting that the deficiencies of children with dyscalculia are specific to the format of numerical input. For example, Rousselle and Noël (2007) found deficits in the processing of symbolic but not non-symbolic stimuli in dyscalculic children. Furthermore, also results within symbolic/nonsymbolic deficits are inconsistent. For non-symbolic number processing (i.e., comparing the numerosity of dot patterns), both group differences between children with and without developmental dyscalculia (Price et al. 2007) but also the absence of group differences (Kucian et al. 2006) were reported. Likewise, for the case of symbolic number processing (i.e., processing of Arabic digits), group differences emerged on number comparison (Mussolin et al. 2010b) and approximate - but not on exact arithmetic (Kucian et al. 2006). Notably, all of the latter studies were targeted at identifying the neural correlates of deficient quantity/numerosity processing, which to date seems to be the most thoroughly validated core deficit of developmental dyscalculia (Wilson and Dehaene 2007).

\subsection{Subtypes of Dyscalculia Due to Domain General Processes}

Nonetheless, as already implied above, the core deficit approach may not be sufficient to account for the complex and often heterogeneous clinical picture of developmental dyscalculia (Kaufmann and Nuerk 2005; Rubinsten and Henik 2009). A first conceptualization of subtypes was proposed by Rourke and colleagues (see Rourke and Conway 1997 for a review). Due to differential performance of children with mathematical disabilities on visuo-spatial and verbal tests (e.g., Rourke and Finlayson 1978), they suggested a visuo-spatial and a verbal subtype associated with either right- or left-hemispheric impairments, respectively. Since then, other subtypes have been proposed. For instance, Geary (1993, 2004) posits three subtypes associated with (i) deficits in verbal working memory assumed to be essential to acquire arithmetic procedures, (ii) deficits in long-term memory as required in building up and retrieving arithmetical facts, and (iii) deficits in processing visuospatial information. Another attempt at subtyping dyscalculia was made by Temple (1991), who presented a double dissociation of impaired arithmetic fact knowledge 
(i.e., deficient multiplication) and impaired arithmetic procedures (i.e., procedural calculation as in subtraction and division). From this, Temple concluded that arithmetic facts and arithmetical procedures develop semi-independently, meaning that neither one seems to be a precursor of the other; a notion hard to reconcile with the hypothesis of a core deficit. In line with this, most of the above described studies suggesting possible subtypes of developmental dyscalculia build upon impaired processes which are not in themselves numerical. Rather, they propose domain general processes of cognitive functioning such as working memory or attention.

\subsection{Subtypes Due to Domain-Specific Numerical Deficits}

When reasoning about subtypes of developmental dyscalculia, one might also be interested in whether there are subtypes defined by specific deficits in particular numerical competencies such as arithmetic fact knowledge (which has initially been proposed by Temple 1991). A first step towards such a conceptualization was suggested by Wilson and Dehaene (2007) based on the differentiation of numerical representations postulated by the Triple Code model of number processing (Dehaene and Cohen 1995, 1997; Dehaene et al. 2003; Dehaene 2009). The Triple Code model discriminates between three different numerical representations: (i) an analogue numerical quantity representation reflecting the semantic magnitude information, (ii) a visuo-spatial numerical representation associated with mental number line representations attentional shifting along this number line, and (iii) an auditoryverbally representation of arithmetic fact knowledge such as multiplication tables. Inspired by this differentiation, the authors proposed three theoretical subtypes of developmental dyscalculia, and even derived neuro-anatomical predictions from the Triple Code model. A first subtype could be a kind of number sense (core deficit) dyscalculia linked to dysfunctions of brain areas around the IPS (Kaufmann et al. 2011; Kucian et al. 2008; Mussolin et al. 2010a; Price et al. 2007) that subserve magnitude processing. As a second potential developmental dyscalculia subtype, they proposed a spatial attention subtype (characterized by difficulties to solve number tasks requiring spatial skills such as locating numbers on a number line), possibly supported by the posterior superior parietal lobule (PSPL). Finally, the verbal subtype (characterized by deficient number fact retrieval, among others) may be linked to anomalous functioning of angular gyrus (AG) and perisylvian areas. Importantly, this conceptualization of developmental dyscalculia (Wilson and Dehaene 2007) represents a hypothetical model and so far lacks empirical confirmation. Nevertheless, it fuels the debate about possible subtypes of developmental dyscalculia no longer motivated primarily by impairments in rather general cognitive processes such as left-/right-hemispheric processing (cf. Rourke 1993) or (working) memory (cf. Geary 1993, 2004). Such different views were recently formalized by Rubinsten and Henik (2009) in different frameworks suggesting abnormalities in different but specific brain areas to underlie specific associated numerical processing deficits. 
Moreover, Rubinsten and Henik (2009) even took one step further and proposed possible frameworks conceptualizing comorbidities of developmental dyscalculia with either ADHD or dyslexia. However, in line with above argument on dyscalculia subtypes we would suggest these subtypes to be associated with impairments of specific basic numerical representations and processes instead of rather general processing characteristics.

In sum, there have been a number of different suggestions which subtypes may be dissociated. While there is certain agreement in the literature on certain subtypes that may be particularly important (e.g., verbal subtype, spatial-attentional subtype), there is still little agreement on how many and which subtypes should be considered. This is probably due to a lack of large-scale multivariate studies (Q-factor analyses, cluster analyses etc.) dissociating different subtypes of dyscalculia. Thus, while there is a large number of single-case descriptions (e.g., Temple 1991) from which hypotheses for subtyping can be generated, there are no largescale multivariate data on whether all dyscalculics can be sufficiently categorized by any subtyping system.

However, for any personality trait a person-oriented and a variable-oriented approach can be dissociated (Eye and Bogat 2006; Stern 1911). While the person-oriented approach describes different persons according to their individual profiles (in our case dyscalculia subtypes), the variable-oriented approach describes different persons according to their performance on variables of interest (in our case different number representations). In dyscalculia, one or more of these representations may be impaired leading to numerical and/or arithmetic deficits. In the following, this variable-oriented view will be further specified with respect to numerical processing by suggesting a differentiation between six basic numerical representations and associated deficiencies in dyscalculia.

\subsection{Numerical Representations and Consequences of Their Specific Impairments}

Over decades of research on numerical cognition, a multitude of representational components has been suggested. The basic numerical components posited and described in the next paragraphs follow the classification of Nuerk et al. (2006; see also Claros-Salinas et al. 2009; Moeller et al. 2009a). Basically, the Nuerk et al. (2006) classification extends and specifies the representations postulated by the Triple Code model (Dehaene and Cohen 1995, 1997; Dehaene et al. 2003). In addition to the visual Arabic, the auditory verbal, and the analogue magnitude code proposed by the Triple Code model, Nuerk et al. (2006, see also Moeller et al. 2009a) suggest three more basic representations: a spatial representation of number magnitude, a representation of the place-value structure of the Arabic number system and finally, a representation of procedural, strategic and conceptual 
numerical knowledge. These six basic numerical representations will be described in greater detail in the following. ${ }^{1}$

\subsubsection{Visual Number Form}

Comparable to the case of reading and writing, the most basic precondition for any understanding and correct application of a symbolic number system is the successful recognition, representation, and mastery of the number symbols. In our Arabic number system, these basic number symbols are the ten digits (i.e., 1, 2, 3, 4, 5, 6, 7, 8, 9, and 0). As any multi-digit number can be composed of these ten digits, their understanding is a vital corner stone of any development of mathematical/ arithmetic capabilities. For instance, the digit 5 needs to be recognized as a digit (as opposed to a letter) and be discriminated from other digits such as 6. Difficulties at this most basic level should be indicated amongst others by problems in number naming and/or writing (also referred to as transcoding). At the same time, understanding of non-symbolic quantities such as dot patterns should be preserved. It follows that a pure form of visual number form dyscalculia should result in clear-cut symptoms in the processing of symbolic numerical information that do not generalize to non-symbolic quantity processing such as reading symbolic number aloud. Temple (1989) termed a respective disorder as digit dyslexia (see also Cohen and Dehaene 2000; Dehaene and Cohen 1995, for patient data). In most diagnostic tests of numerical abilities, the correct understanding of the visual number form is not assessed explicitly. This is because this component is preserved in most children suffering from dyscalculia. Nevertheless, for any kind of remediation programme it is essential to evaluate whether the observed numerical impairments originate from this very basic representation of visual number forms. Training of more advanced numerical capabilities can only be successful when a child is able to recognize and discriminate between the used symbols.

\subsubsection{Semantic Representation of Numerical Magnitude}

There is accumulating evidence suggesting that both children and adults automatically activate at least an approximate quantity representation (e.g., Dehaene et al. 1993; Rubinsten and Henik 2005; Gebuis et al. 2009, for children data) when

\footnotetext{
${ }^{1}$ It is important to note that this differentiation into six basic representations is open to the discussion whether these representations are domain-general, domain-specific, or an interaction of both. For instance, the verbal representation of numbers (e.g., arithmetic facts) may be impaired as a consequence of a deficit in a specific numerical domain or as a domain-general deficit (impaired verbal retrieval of any semantic facts). While this issue is important, it is not the main focus of the present section, in which we want to argue that numerical competence relies on certain underlying basic representations, but do not wish to make assumptions about where an eventual deficits stems from.
} 
confronted with either symbolic (e.g., Arabic digits) or non-symbolic (e.g., dot patterns) magnitudes. Thereby, numerical magnitude information becomes instantaneously available and may allow for a primary estimation/evaluation of possible results in any kind of numerical tasks (e.g., $2+4=9$ ). This is possible even before explicit magnitude manipulations are conducted to calculate the actual result. As this magnitude representation reflects the primary semantic information conveyed by numbers and/or numerosities, its impairment results in severe deficits on all numerical tasks involving the processing of magnitude information in any form. These tasks include magnitude comparisons, but also number bisection tasks or arithmetical operations like subtraction. Additionally, because magnitude information is the semantic key property of any number, an impairment of this magnitude representation represents a deficit right at the heart of any numerical understanding. In accordance with above considerations on a core deficit underlying developmental dyscalculia, an impairment of this basic numerical representation may be the best candidate to cause such a core deficit of the number sense (cf. Wilson \& Dehaene 2007). However, within the present conceptualization, an impaired magnitude representation may be a sufficient cause for developmental dyscalculia, but not a necessary one. Nevertheless, there is ample empirical evidence that children diagnosed with developmental dyscalculia often exhibit an impairment of their number magnitude representation (Ashkenazi et al. 2008; Holloway and Ansari 2009; Rousselle and Noël 2007; Kaufmann and Nuerk 2008; Moeller et al. 2009b).

\subsubsection{Verbal Numerical Representations}

Subsumed under the term of verbal numerical representations there are at least two important but at a first view very different numerical concepts. On the one hand, auditory-verbal representations of number words such as "seven" but also more complex ones like "one hundred eighty four" are denoted by this term. Often the acquisition of counting sequences and thus the first number words represents an initial step in the development of numerical cognition. However, in this context it should be noted that the composition of number words is not consistent across languages but shows great inter-language variability. Apart from specific number words (e.g., Eighty in French "quatre-vingt" can be translated literally as "4 times twenty") one of the most important differences concerns the inversion of the order of tens and units in two-digit number words of some languages. For instance, in German (but also in Maltese, Arabic, etc.) 47 is spoken as "siebenundvierzig" (literally "seven-and-forty") and thus the order of tens and units is reversed in number words as compared to symbolic digital notation. This seems to influence numerical development even later on, as it is assumed that typically developing children but also adults verbally recode digitally presented numbers while e.g., performing calculations to keep track of partial results and the calculation procedure (see Helmreich et al. 2011; Pixner et al. 2011, for influences of different verbal number word systems on non-verbal numerical cognition in children; Nuerk et al. 2005 for adult data; Nuerk et al. 2011 for a review). 
Despite the straightforward involvement of verbal number words, the second important aspect of verbal numerical representations are the so-called arithmetic facts which are assumed to be stored in an auditory-verbal manner (cf. Dehaene and Cohen 1997; Dehaene et al. 2003). For instance, after multiplication tables are highly overlearned during primary school, it is widely agreed that single-digit multiplications do not have to be actively calculated any more (e.g., Ashcraft 1987; Campbell 1995; McCloskey and Lindemann 1992; Rickard 2005; Siegler 1988, see Delazer et al. 2003, 2005; Ischebeck et al. 2006 for fMRI data on multiplication learning). Instead, it is assumed that multiplication (but also small addition) problems together with their results have become long-term memory entries of a verbally mediated network. In the case of an impaired verbal representation the most noticeable symptom should be a severe lack of arithmetical fact knowledge. For instance, children suffering from arithmetic fact dyscalculia should resort to more time-consuming back-up strategies in multiplication, such as computing each result through repeated addition instead. As already noted above, there is empirical evidence corroborating the existence of such specific deficits in arithmetic facts retrieval (also termed number fact dyscalculia, Temple 1991; or long term memory subtype, Geary 1993).

\subsubsection{Spatial Representation of Numerical Magnitude}

Since the seminal work by Galton (1880) back in the nineteenth century, a representational association of numbers and space has become widely accepted. Often, the spatial numerical representation is described by the metaphor of a mental number line along which numbers are represented in ascending order with respect to their magnitude (cf. Restle 1970; Dehaene and Cohen 1995). Initially, Berch et al. (1999) observed that typically developing children exhibit such spatial numeric representations by the end of primary school. However, more recent studies suggest a spatial numerical representation as early as grade one (van Galen and Reitsma 2008) or even earlier (e.g., de Hevia and Spelke 2009, 2010; McCrink and Wynn 2009; Opfer and Furlong 2011; Opfer and Thompson 2006). Additionally, it was found that a good spatial representation of number magnitude (as for instance assessed by the number line task, in which children have to estimate a numbers position on a hypothetical number line) is not only correlated with actual arithmetic achievement but is also a reliable predictor for the successful learning of new arithmetical problems (Booth and Siegler 2008). This indicates that an educated spatial representation of numerical magnitude seems to be beneficial for the general representation, understanding, and application of number magnitude information. Moreover, empirical evidence suggests an interrelation of more general visuospatial deficits and numerical performance. In this context, Bachot et al. (2005) found that the prevalence of mathematical difficulties was significantly higher for children with deficits in the general processing of visuo-spatial information (see also Rourke and Finlayson 1978 for a corresponding subtype of developmental dyscalculia). 
However, concerning multi-digit numbers another influence of spatial-numerical representations has to be acknowledged: the impact of the place-value structure of the Arabic number system (see above). It has been observed repeatedly (e.g., Siegler and Booth 2004; Moeller et al. 2009c; Helmreich et al. 2011) that children initially do not adhere to the equidistance relation between numbers as indicated by the base-10 property of the Arabic number system (i.e., the distance between 0 and 60 is exactly 10 times the distance between 0 and 6). In the view of the interrelation between numbers and space, these findings suggest specific influences of spatial information on multi-digit number processing even in children. This conclusion can be drawn because the differentiation between the stack slots complying with the place-value structure of the Arabic number system is actually based on spatial information. Consequently, a related specific dyscalculic deficit may present with specific problems transcoding multi-digit numbers due to inefficient integration of the spatially coded stack information. Additionally, these children should be specifically impaired in tasks such as the number line estimation task which require an externalization of the spatial representation of numerical magnitude.

\subsubsection{Representation of the Place-Value Structure of the Arabic Number System}

Besides representations of the visual number form of digits and their semantic magnitude information there is another specific numerical representation which is inevitably necessary to correctly represent and use multi-digit numbers in particular - a representation of the place-value base-10 structure of the Arabic number system. Whenever confronted with multi-digit numbers, one needs to assign each individual digit its place-value stack information to correctly derive the number's overall magnitude. Throughout development, children need to learn how to identify units, tens, hundreds, etc. correctly to become aware of the fact that although 28 and 82 are composed of the same digits, they differ considerably in their magnitudes. According to their different places within the digit string, the digits are assigned different stack values (e.g., 2 at the tens, i.e., 28 vs. at the units' position, i.e., 82). The necessity of understanding the place-value structure to master basic numerical tasks such as magnitude comparison but also arithmetic implies specific effects of such place-value integration processes on arithmetic performance. And in fact, Nuerk and colleagues observed reliable effects of place-value integration in magnitude comparison for both children and adults (Nuerk et al. 2001, 2004a, b, 2005; see Mann et al. 2011 and Pixner et al. 2009 for children data; see also Macizo and Herrera 2010; Ganor-Stern et al. 2009; Zhou et al. 2008; see Nuerk et al. 2011, for a review). When separate comparisons of tens and units yielded compatible decision biases (e.g., 32_57, $3<5$ and $2<7$ ), the larger of two numbers was identified faster than when these comparisons yielded incompatible biases (e.g., 37_62, $3<6$ but $7>2$, see Nuerk and Willmes 2005 for a review). Additionally, there is now first evidence that the carry effect in addition may also be interpreted as a specific effect of place-value integration as tens and 
units are processed differentially (Klein et al. 2010; Moeller et al. 2011a, b). Furthermore, recent studies suggest that the structure of the number word system of a language (with/without inversion) may have particular influences on the successful acquisition and application of place-value information (Helmreich et al. 2011; Pixner et al. 2011). Generally, children whose number word system is inconsistent with the Arabic notation (i.e., because of an inversion of tens and units as e.g., in German number words; $64 \rightarrow$ four and sixty) are at a disadvantage for acquiring the place-value structure of the Arabic number system successfully (e.g., Miura et al. 1993, 1994; Towse and Saxton 1998). In line with these findings, developmental dyscalculia caused by an impaired place-value representation should manifest itself for instance by an increased carry effect in addition.

\subsubsection{Strategic, Conceptual and Procedural Components}

Compared to the former numerical representations that reflect more or less very basic components of numerical cognition this last conceptualization addresses representational aspects primarily involved in/required for the solution of more complex numerical/arithmetic tasks and problems. As a consequence, the specific components subsumed under this last headword are less unitary than those described above and may be further differentiated by future research. However, for the purpose of the current chapter it is sufficient to illustrate that apart from the very basic representations serving as a building block for the development of higher numerical cognition there are of course arithmetical strategies, numerical concepts and procedures that may involve more than just one of the above described representations. For instance, the carry effect in addition may serve as an example of how different representations are recruited and applied in an arithmetic procedure to solve the task at hand. Consider the problem $27+48=75$. First, the individual digits need to be identified correctly. Then, following the standard algorithm the sum of the unit digits has to be computed first by either manipulation of semantic magnitude representations or fact retrieval of single-digit addition facts. As the sum of the unit digits is larger than 10, its decade digit needs to be carried to the tens stack of the place-value structure of the Arabic number system, which requires place-value knowledge. All these single steps together may then represent the procedural rule for correctly solving a carry addition problem. For both children and adults it is known that carry addition problems take more time and are more error prone than comparable non-carry problems. Therefore, these have to be trained specifically during primary school. The latter may be of particular importance as there is accumulating evidence for the suggestion that the neural correlates of procedural components are localized differently as compared to basic numerical representations such as number magnitude knowledge. On the one hand, it is widely agreed that processing of number magnitude information is subserved by (intra)parietal cortex sites (Wood et al. 2008; Dehaene et al. 2003; Dehaene 2009). On the other hand, procedural, conceptual, and strategic processes as well as related processes of cognitive control and working memory have been associated 
repeatedly with (pre)frontal cortex (e.g., Burbaud et al. 2000; Delazer et al. 2005; Miller 2000). With regard to specific deficiencies in developmental dyscalculia, we posit that there may be children who suffer from deficient procedural processing (cf. Geary 1993; Temple 1991), even though they successfully acquired all of the above described representations. In such a case, an affected child should show no specific impairment on any of the individual representations. Instead, the child should experience an extraordinarily increased difficulty of task and/or problems that require the correct application of procedural arithmetic rules (e.g., specific problems executing carry and/or borrowing operations in addition/subtraction), choices of solution strategies, or the application of conceptual knowledge (i.e., $0 \times \mathrm{X}$ is always 0 ).

Before turning to the next point on the diagnostics of developmental dyscalculia, one important note has to be made. Above, following the description of each basic numerical representation, we made suggestions about how an isolated deficit in any of the specific representations could manifest itself in numerical or arithmetic difficulties. However, these descriptions should only be seen as suggestions to illustrate the multi-componential variable-oriented view on numerical cognition we wish to advocate. We are confident that the described basic representations will prevail as an important foundation of numerical cognition. There is, however, a number of issues that have to be considered concerning the above description.

First, the postulated representations may not be exhaustive. For instance, the representation of strategic, conceptual and procedural processes may need to be further differentiated. Moreover, recent findings suggest that embodied representations of numerical representations that are based on finger counting processes may also play an important role in numerical or arithmetic functioning (Domahs et al. 2008, 2010; Fischer 2008; Lindemann et al. 2011). Complementing these findings, another line of research has found evidence that finger gnosis might be important for numerical development (e.g., Gracia-Bafalluy \& Noël 2008). Therefore, future descriptions might incorporate an embodied representation of finger counting, finger gnosis, or finger quantity.

Second, we do not wish to rule out the possibility that any of the described deficits might also induce problems in areas of cognitive processing other than the numerical domain. For instance, it is well conceivable that a fact retrieval deficit may not be restricted to numerical facts, but may also involve other less circumscribed deficits such as impaired retrieval of any kind of semantic information, such as a general (verbal) memory deficit that also extends to numerical information. In the above description of the six basic numerical representations, we only aimed at illustrating the importance of a verbal representation of numbers for numerical and arithmetic functioning and that its impairment may be detrimental for numerical performance. However, whether the causal reason for an observed impairment is a domain-general or a domain-specific deficit is still a matter of debate. Quite possibly, there may not even be a general answer to this issue, as recent data indicate that variation in numerical cognition is also subject to individual differences (e.g., Grabner et al. 2007; Ischebeck et al. 2009; see Dowker 2005 for implications on numerical development and education). In our view, such individual differences 
might also be found in children. Consequently, impaired arithmetic fact retrieval might be a result of a domain-specific deficit in one child while in another child it might be the result of a broader, domain-general deficit of semantic fact retrieval also extending to arithmetic facts. However, these considerations are not limited to the verbal representation of numbers. For instance, also deficits in procedural and strategic processing could be domain-specific but might as well be domain-general and generalize to other domains of cognitive processing such as reading and writing. In any case, we postulate that such elementary processes underlie complex numerical cognition and thus have to be functioning so that complex arithmetic tasks can be mastered.

Third, and finally, identifying basic numerical dimensions in a variable-oriented approach does not preclude the possibility that there are different profiles (e.g. certain combinations of impairments) manifesting themselves in different dyscalculia subtypes. While we favour a variable-oriented approach to describe dyscalculic dysfunctioning, the current data do not preclude the validity of a person-oriented profile approach (i.e., subtyping). In our view, to date this issue is still debatable because of the lack of large-scale multivariate data (e.g., Q-factor analyses, cluster analyses, discriminance analyses) testing large samples of children with dyscalculia over a broad range of variables that index different numerical and non-numerical representations. Such analyses could reveal whether certain profiles of dyscalculic deficiencies (i.e., subtypes) can be reliably clustered. Obviously, such large-scale studies on dyscalculia are difficult to conduct because of the immense research effort. However, we suggest that this kind of study is exactly what is needed to progress in understanding reliable differences within dyscalculia regarding both the grouping of variables (numerical representations) and/or persons (profiles of dyscalculia subtypes).

\section{Diagnostics of Developmental Dyscalculia}

A necessary prerequisite for any reliable diagnosis is a consensual definition of the to-be-diagnosed impairment or disorder. Only when it is explicitly specified which criteria must or should be met, a valid diagnosis can be made. However, while this has been more or less accomplished in the case of dyslexia (Consensus project 2002), there is as of yet no universally accepted definition of developmental dyscalculia. In fact, in our view, we are in urgent need of a similar Consensus Project for dyscalculia. Nevertheless, as a working base the two prominent classification systems ICD-10 (World Health Organization 1992, Version 2007) and DSMIV-TR (American Psychiatric Association 2000) can be used that now include disorders of arithmetical/mathematical skills, even though the term developmental dyscalculia is not used explicitly. 


\subsection{Diagnostic Criteria and Prevalence Rates: The Inconsistency Problem}

According to ICD-10 a Specific Disorder of arithmetic skills (code F81.2) is described as a specific impairment of arithmetic skills not entirely attributable to general mental retardation or inadequate schooling. Additionally, the deficit has to primarily involve the mastery of basic computational competencies such as the basic arithmetic operations rather than impairments in more abstract mathematical domains such as algebra or calculus.

On the other hand, DSM-IV-TR criteria for a Mathematics Disorder (code 315.1) include a mathematical ability [...] that falls substantially below the arithmetical/ mathematical capabilities of a child as expected on the basis of the individual's chronological age, her/his measured intelligence, and/or age-appropriate education. Furthermore, the deficient mathematics abilities have to interfere significantly with everyday life but also with academic achievement.

Taken together, it is evident that even the criteria of these two definitions do not match entirely. In fact, both imply a discrepancy criterion as regards mathematics abilities and general intelligence. However, while the DSM-IV-TR standards also include discrepancy diagnosis with respect to chronological age and-age appropriate education, ICD-10 does not explicitly refer to these criteria. Accordingly, the discrepancy criterion is used in research on developmental dyscalculia (e.g., Kosc 1974; Lewis et al. 1994; Fuchs et al. 2005; but see Fletcher et al. 1998; Siegel and Ryan 1989, for critical discussions of the reliance upon the discrepancy criterion, see also Weber et al. 2002, for results suggesting no difference of intervention effects for children either fulfilling the discrepancy criterion for dyslexia or not). Nevertheless, the discrepancy necessary for a diagnosis of dyscalculia varies from study to study (e.g., 2 years between chronological age and actual achievement level as used by Shalev 2004; Shalev et al. 2000; Shalev and Gross-Tsur 2001; e.g., discrepancy $>15$ points between standardized IQ and mathematics achievement test scores, Mazzocco and Myers 2003). Interestingly, these are not the only (and maybe not even the most widely used) diagnostic criteria/definitions of developmental dyscalculia in dyscalculia research. More often than the discrepancy criterion a simpler - and often more convenient - cut-off criterion is applied. However, as in the case of the discrepancy criterion there is currently no generally agreed cut-off for a dyscalculia diagnosis. In the literature, different cut-off criteria are either reported as percentiles (e.g., percentiles <35 e.g., Geary et al. 2000; Jordan et al. 2002; percentiles <25, e.g., Koontz and Berch 1996; McLean and Hitch 1999; percentiles <15, e.g., Geary et al. 2008; percentiles <10, e.g., Geary et al. 2007; Mazzocco and Myers 2003; Murphy et al. 2007), deviations from the population mean in SD (i.e., 1.5 SD, e.g., von Aster et al. 2007; 2.0 SD, e.g., Piazza et al. 2010; Ashkenazi and Henik 2010; 3.0 SD, e.g., Landerl et al. 2004) or ranges of standard scores such as for instance the bottom 2 stanines (Butterworth 2003). Obviously, it is not satisfactory that each diagnostic classification system and what is more even each research group applies their own preferred definition of developmental 
dyscalculia or math impairments. Consequently, the question arises which one of these diagnostic criteria provides the best assessment of developmental dyscalculia.

Mazzocco and Myers (2003) addressed this important issue by directly comparing the application of discrepancy and cut-off based criteria in a longitudinal study on 210 children from kindergarten to grade three. Generally, the authors observed that a cut-off based diagnosis of dyscalculia was more reliable than a diagnosis based on the discrepancy between IQ and mathematics achievement score (see also Marx et al. 2001; Weber et al. 2002 for similar results suggesting no difference for children with dyslexia either fulfilling the discrepancy criterion or not). Furthermore, they found that the two diagnostic criteria did not overlap much. Hence, the majority of children diagnosed to suffer from dyscalculia by their mathematics achievement falling below the 11th percentile did not meet the discrepancy criterion and vice versa. However, the superiority of the cut-off based diagnosis became particularly evident when the longitudinal design of the study was taken into consideration. Concerning the longitudinal validity of the diagnosis, the authors reported that out of all children who ever met the cut-off criterion, 63\% exhibited persistent impairments (i.e., performance $<11$ th percentile over two or more years). In contrast, persistency was considerably lower (i.e., 18\%) when the discrepancy based criterion was applied.

In summary, these data argue for the superiority of the cut-off based over the discrepancy based diagnosis of dyscalculia and call for a revision of the diagnostic classification systems. However, these data do not suggest that IQ assessment in general is no longer useful - they only demonstrate that the absence of a discrepancy between IQ and mathematics achievement does not preclude the occurrence of developmental dyscalculia. Thereby, the discrepancy criterion may provide considerable specificity for detection of dyscalculia but may lack sufficient sensitivity to identify all children affected by dyscalculia (see also Mazzocco and Myers 2003 for a more detailed discussion of this point). Moreover, the results of Mazzocco and Myers (2003) indicate that a single time assessment of numerical/ mathematical capabilities using only one single test may not be sufficient to warrant a reliable diagnosis of dyscalculia. Instead, due to incidence figures varying both at one given point in time as well as over the course of time, the relevant numerical/ mathematical abilities should be assessed several times using different tests. This would make it possible to assess another criterion which has been suggested in recent years as an alternative to discrepancy or cut-off based diagnostics. Based on findings that dyscalculic children still struggle with retrieving basic arithmetic facts even after extensive training (e.g., Howell et al. 1987), Geary (2004) argues that such treatment resistance in itself may also be a valid diagnostic criterion of dyscalculia (see also Mazzocco and Myers 2003 for a similar rationale).

In a nutshell, because of these inconsistencies in dyscalculia definitions as well as diagnostic standards, it is not surprising to learn that the reported prevalence rates differ from study to study. Nevertheless, across different countries and continents, similar prevalence rates between about $3 \%$ and $10 \%$ of the overall population suffering from developmental dyscalculia have been observed (Kosc 1974; Badian 1983; Klauer 1992; Lewis et al. 1994; von Aster 1994; Gross-Tsur et al. 1996; Ostad 1998; Shalev et al. 2000; Shalev and Gross-Tsur 2001; Ramaa and Gowramma 2002; Mazzocco and Myers 2003; Koumoula et al. 2004; von Aster et al. 2007) 
Taken together, the above literature denotes that the absence of a universally agreed definition of developmental dyscalculia together with non-uniform diagnostic criteria caused great heterogeneity in existing dyscalculia diagnostics, since cut-offs and discrepancy measures are picked more or less arbitrarily. As a consequence, prevalence rates observed on the basis of these differing diagnostic criteria differ as well, and primarily serve as educated guesses, rather than elaborated estimations of the actual prevalence rates of dyscalculia. Therefore, we would like to offer a unifying approach on diagnostic criteria of developmental dyscalculia by taking into account the above considerations on specific basic numerical competencies and related dyscalculic deficiencies.

\subsection{Towards a More Specific Diagnosis of Developmental Dyscalculia}

Apart from the psychometric and methodological shortcomings and limitations, the definition of the ICD-10 Specific disorder of arithmetical skills and of the DSM-IV Mathematics Disorder also provide links to the above described reasoning on actually impaired competencies and subtyping. For instance, in ICD-10 one can find further specifications as regards the kind of impairments observed in developmental dyscalculia. In line with our considerations, primary impairments of rather basic numerical abilities are suggested even though these are not described at the representational level but at the level of basic arithmetical operations. Interestingly, this approach is corroborated by a recent review of dyscalculia interventions and remediation programs currently in use in the UK (Dowker 2009). Dowker argued that training of rather basic numerical competencies seems to be most beneficial for dyscalculic children. Therefore, it is only plausible to address basic numerical capabilities in dyscalculia diagnostics to narrow down the specific origin of the deficits individually - rather than adopting a more or less broad label of deficient numeracy. At the moment, such specific information about children's differential performance on particular tasks and/or subtests is often not fully exploited. In this vein, Geary (2004, p. 5) remarks that "Standardized achievement tests sample a broad range of arithmetical and mathematical topics, whereas children with MLD often have severe deficits in some of these areas and average or better competencies in others". Thus, the use of sometimes quite liberal cut-offs for the diagnosis of dyscalculia (e.g., <26th percentile, cf. Koontz and Berch 1996; McLean and Hitch 1999) may be due to the fact that no specific and differential evaluation of the basic numerical competencies has been conducted. Instead, the $25 \%$ cut-off may have been chosen to compensate for the averaging across items assessing different competencies. Therefore, to overcome the shortcoming that such results indicate "a level of performance (e.g., at the 20th percentile) that overestimates the competencies of children with MLD in some areas and underestimates them in others" (Geary 2004), we recommend to diagnose dyscalculia by combining general task performance measures with performance measures for individual subtests. 
Table 1 Overview of suggested cut-offs for dyscalculia diagnostics

\begin{tabular}{ll}
\hline Percentile & Suggested diagnosis \\
\hline $\begin{array}{c}\text { Overall performance } \\
\text { above 25th percentile }\end{array}$ & No indication of developmental dyscalculia \\
$\begin{array}{c}\text { Between 25th and } \\
11 \text { th percentile }\end{array}$ & At risk for developmental dyscalculia \\
$\leq 10$ th percentile & Developmental dyscalculia \\
$\begin{array}{l}\text { Specific subtests } \\
\leq \text { th percentile }\end{array}$ & $\begin{array}{c}\text { Specific developmental dyscalculia (indicative of specific deficiencies } \\
\text { in specific numerical processes) }\end{array}$ \\
\hline
\end{tabular}

First of all, we suggest classifying all individuals scoring $\leq$ the 25 th percentile on a standardized test as being at risk for dyscalculia. Furthermore, individuals whose general performance was $\leq 10$ th percentile should be diagnosed with developmental dyscalculia (see also TEDI-MATH, Kaufmann et al. 2009a). Alternatively, a specific dyscalculia deficit diagnosis should be warranted if the individual scores $\leq 5$ th percentile on at least an a priori defined number of subtests - the latter indicating specific impairments of the particular competencies addressed by these subtests. Thereby, under the precondition of existing tests being standardized at the subtest level, such a proceeding should allow for a reliable diagnosis of developmental dyscalculia in general. In addition, it allows for direct assessment of certain deficits by examination of critical differences between subtests. Additionally, very specific dyscalculic deficits (such as postulated above) can be identified by taking into account those subtests in which a person performs $\leq 5$ th percentile, and be diagnosed even when general performance is still above the 10th percentile (see Table 1 for an overview).

To better illustrate how such a differential dyscalculia diagnosis could be achieved, we will describe the German version of the TEDI-MATH (Kaufmann et al. 2009a) as an example. This test was designed specifically for the diagnosis of developmental dyscalculia and therefore differentiates best in the range of low performance. Beside a total score, the individual subtest scores can be integrated into two subscale scores: Numerical Processing (subtests including, for example, Counting Principles, Arabic Digit Comparison, and Numerical Transcoding) and Calculation (for example Addition, Subtraction, Word Problems, and Knowledge of Arithmetic Concepts). As the TEDI-MATH was standardized on the subscale level, it should be possible to base a diagnosis on specific performance dissociations between some of the subtests. For instance, one of the basic numerical representations we introduced above, the Verbal Numerical Representation (consisting of both the knowledge of spoken number words and verbally stored arithmetic facts), is addressed by several subtests of the TEDI-MATH (Kaufmann et al. 2009a): the subtests Recognition of Number Words, Transcoding, and Multiplication. These subtests measure how well children can discern number words from non-numerical verbal stimuli, whether children can correctly read and write numbers, and how well children can retrieve verbally stored multiplication tables, respectively. The standardized norms for each subtest of the TEDI-MATH make it possible to determine whether a child performs $\leq 5$ th percentile on these subtests. If this is 
the case, we suggest that a diagnosis of a verbal dyscalculia deficit should be warranted even if the child performs in the average range on all other subtests and even though its total score may lie above the 10th percentile (see e.g., Temple 1991 for a dissociation of number fact and procedural dyscalculia).

This approach on subtyping seems particularly important regarding the differentiation of basic numerical competencies but also the latest DSM-IV-TR definition of Mathematics Disorder. Here, one can read that "a number of different skills may be impaired in Mathematics Disorder, including "linguistic" skills (e.g., understanding or naming mathematical terms, operations, or concepts, and decoding written problems into mathematical symbols), "perceptual" skills (e.g., recognizing or reading numerical symbols or arithmetic signs, and clustering objects into groups), "attention" skills (e.g., copying numbers or figures correctly, remembering to add in "carried" numbers, and observing operational signs), and "mathematical" skills (e.g., following sequences of mathematical steps, counting objects, and learning multiplication tables)". As these different "skills" can be easily associated with above described basic numerical representations (e.g., linguistic skills $\rightarrow$ verbal numerical representations; mathematical skills $\rightarrow$ procedures, concepts, and strategies), this definition emphasizes the importance of a reliable diagnosing of the specific impairments in developmental dyscalculia.

Admittedly, to fully exploit the potential of such a multi-componential differential diagnosis of dyscalculia, further research and psychometric development is necessary to provide the required standardized tests. To date, only a very limited number of tests has been standardized at the subtest level [e.g., CMAT (Hresko et al. 2003; TEMA-3 (Ginsburg and Baroody 2003); TOMA-2 (Brown et al. 1994); ZAREKI-R (von Aster et al. 2006); TEDI-MATH (Kaufmann et al. 2009a, b)].

In this context, it is necessary to investigate in which way the postulated basic numerical representations are interrelated and influence one another (e.g., Wood et al. 2008; Nuerk et al. 2002). Additionally, there is still a lack of understanding how far basic numerical representations are influenced by surface formats such as numerical notation (i.e., possible differing representations of symbolic or nonsymbolic magnitude). Finally, when aiming at studying developmental dyscalculia transculturally, the development of appropriate dyscalculia tests should be coordinated across cultures and nations - thereby, enhancing the comparability of international studies on developmental dyscalculia. Otherwise, even when relying on agreed criteria, different children might be selected still when using different tests with different subcomponents.

To sum up, in line with our proposition of possible dyscalculia diagnoses (see Table 1) being associated with specific impairments of basic numerical representations, we suggest multi-componential differential diagnostics for developmental dyscalculia. In our opinion, this would not only allow for a better understanding of the actual individual impairment(s), but would also pave the way for more tailored intervention programmes adapted to the needs of each individual with dyscalculia. From a practical point of view we have to admit that the prerequisite for such elaborate in-depth diagnostics is still in its fledgling stages with only few appropriate tests. These few tests, however, provide the required differentiation and thus a 
first step towards more comprehensive understanding of developmental dyscalculia as well as its causes, deficiencies and remediation.

As regards a comprehensive understanding of developmental dyscalculia, it is important to not only concentrate on issues of theoretical underpinnings and diagnostics but also to consider its comorbidities with other developmental disorders such as dyslexia and/or ADHD. In the following paragraphs this issue will be pursued.

\section{Developmental Dyscalculia and Comorbid Developmental Disorders}

Generally, a so-called comorbidity is given by the presence of coexisting or additional diseases with reference to an initial diagnosis or to the index condition that is the subject of study (i.e., developmental dyscalculia in the present case). As for other (developmental) cognitive disorders it is an important point to know or to at least have a reliable estimate of the rate at which developmental dyscalculia co-occurs with other cognitive impairments such as dyslexia. Often, it is a multimorbid pathology that is recognized by either teachers or parents, and background knowledge about the interrelation of co-occurring developmental disorders should be mandatory for a differential diagnosis and the later decision on remediation. At this point, we would like to once again emphasize the importance of a differential diagnosis of developmental dyscalculia. Of course, arithmetic difficulties can also arise not as a primary impairment of numerical competencies but also as the secondary result of a different (developmental) cognitive disorder, such as, for instance, ADHD. In this case, treatment of the primary impairment should be the main focus of intervention. Such a secondary symptomatology, however, does per definition not qualify as a comorbidity or co-occurrence in the narrower sense and will therefore not be elaborated on in this section (see e.g. Rubinsten 2009; Rubinsten et al. 2008; Kaufmann and Nuerk 2008 for numerical impairments in children with ADHD). However, it is important to note that general developmental cognitive disorders can exert an influence on numerical processing as well as on other cognitive domains, which, when not considered as a mediating variable, may lead to an overestimation of co-morbidity.

\subsection{Comorbidity Rates}

In this context, the comorbidity rate is one important index reflecting the percentage or proportion of children suffering from developmental dyscalculia that also exhibit considerable symptoms of, for instance, dyslexia.

As we have few data on comorbidity of dyscalculia to date, a look on the much better studied impairment of dyslexia might be helpful. For the case of 
dyslexia the comorbidity rates reported in the literature vary considerably between $17 \%$ and $70 \%$ of children with dyscalculia also showing reading problems and 11-56\% of children with dyslexia also suffering from dyscalculia (Badian 1983; Barbaresi et al. 2005; Dirks et al. 2008; Gross-Tsur et al. 1996; Lewis et al. 1994; von Aster et al. 2007). The enormous variation in this comorbidity estimates clearly suggest that the criteria defining developmental dyscalculia differ between studies (see also above) and do not yet provide reliable comorbidity estimates. Therefore, it is necessary to take a closer look on this methods before reporting any conclusive numbers.

\subsubsection{Empirical Comorbidity Rates and Cut-off Criteria}

In a recent article, Landerl and Moll (2010) argue that there are several reasons for this high variability in comorbidity rates in contrast to the rather stable prevalence estimates. On the one hand, the authors point out that academic achievement tests of e.g., arithmetic, often comprise word problems that children with reading difficulties have troubles solving even when they are not dyscalculic. Therefore, the overall achievement score derived by most arithmetic achievement tests might be confounded because not only the capabilities of interest are assessed. Instead, successful mastery of the arithmetic problems depends on other capabilities such as reading ability that are not explicitly assessed. This reasoning further corroborates our recommendation of a thorough differential diagnostic of the actually impaired numerical representations/competencies to avoid such confounding.

Moreover, Landerl and Moll (2010) suggest that comorbidity rates may be inflated not only by the use of averaged general achievement scores (instead of performance profiles), but by the selection criteria applied for diagnosing either dyscalculia or any other disorder. Accordingly, comorbidity increases with more liberal selection criteria. In this context, Dirks et al. (2008) were able to show that the comorbidity rate for dyscalculia and dyslexia declined from $7.6 \%$ to about $1.0 \%$ when employing a selection criterion of performance $\leq 10$ th percentile as compared to $\leq 25$ th percentile. Interestingly, this reduced comorbidity rate of $1.0 \%$ reflects exactly the rate of co-occurrence expected by chance when assuming two unrelated disorders. More light is shed on this interrelation by the results of Landerl and Moll (2010). These authors assessed comorbidity rates of dyscalculia and dyslexia in a population based sample as well as in a subsample with learning disorder(s). In line with the results of Dirks et al. (2008), Landerl and Moll (2010) observed that comorbidity rates between these two disorders decreased when applying a more stringent cut-off. Additionally, they found that comorbidity rates for the learning disabled sample were generally higher (and particularly so for the stricter cut-off) than those observed for the population based sample. Thus, liberal selection criteria as well as the examination of preselected populations such as children with learning disorders seem to increase comorbidity rates. In general, more liberal selection criteria are assumed to lead to less homogeneous and thus probably more multi-morbid deficit groups. When then evaluating the comorbidity 
rate of any two developmental disorders, it is very likely to find these rate being inflated by the preselection of the sample. This skepticism regarding the reported comorbidity rates is also corroborated by a recent study on dyscalculia by Auerbach et al. (2008). The authors assessed behavioral problems in a sample of adolescents with persistent dyscalculia. Interestingly, they observed only few and rather unsystematic evidence suggesting more attentional and/or externalizing problems in adolescents with dyscalculia.

\subsubsection{A More Theoretical View on Comorbidity Rates}

Despite the fact that above rationale suggests decreasing comorbidity rates with more stringent cut-off criteria, there is also evidence suggesting that comorbidity increases with the severity of one developmental disorder (e.g., Landerl and Moll 2010). Thus, contrary to what has been described above this means that a child should exhibit more co-occurring conditions the more severe the primary disorder (e.g., Jordan and Montani 1997; Kaplan et al. 2006). For any combination of developmental disorders, such phenomena are often interpreted as suggesting a common neuro-biological basis of the two disorders at hand (in terms of pleiotropy, e.g., Pennington 2006) or complex downstream effects in brain development (e.g., Kaplan et al. 2006).

To illustrate this argument, consider the case of attentional and arithmetic deficits. For both cognitive functions, there is ample evidence associating its neural correlates with parietal cortex sites in and around the intraparietal sulcus (e.g., Simon et al. 2002). Accordingly, when impaired arithmetic skills are attributed to dysfunctional neural processing at these cortical sites that overlap with those involved in attentional processes, then attentional deficits should get more pronounced the more neural processing of numerical information is impaired. Following this rationale, comorbidity rates should increase, rather than decrease, for more stringent selection criteria; reflecting the common neural underpinnings of the comorbid disorders. However, most of the empirical evidence suggests that comorbidity rates increase with more liberal cut-off criteria. Nevertheless, there is also contrasting evidence indicating increasing comorbidity rates with more stringent cut-off criteria (e.g., Landerl and Moll 2010). The latter findings are of particularly relevance when taking into account the notion of common neural bases of the comorbid disorders. And indeed, in such a case, differential evaluation of comorbidity rates for diverse developmental disorders may offer the possibility to gain further insights into the connectivity of the human brain and its differential contribution to seemingly distinct cognitive functions.

For instance, assuming that comorbidity of disorders $\mathrm{A}$ and $\mathrm{B}$ decreases for more liberal cut-offs while the co-occurrence of disorders $\mathrm{A}$ and $\mathrm{C}$ increases, this would indicate a closer relationship (in terms of neural correlates) of disorders $\mathrm{A}$ and B compared to A and C. Importantly, Landerl and Moll (2010) found such a dissociation for the comorbidity of arithmetic and spelling v.s. arithmetic and reading deficits. While the rate of co-occurrence for arithmetic and reading deficits 
decreased when stricter selection criteria were applied, the comorbidity rate of arithmetic and spelling deficits did not. The authors interpret this data pattern to suggest a more pronounced biological mediation of the comorbidity between arithmetic and spelling disorders. Thereby, Landerl and Moll (2010) provide a first account of how to not only interpret but make use of the inconsistent empirical evidence as regards the interrelation of comorbidity rates and cut-off criteria selection. Bridging the gap between the two assumptions on comorbidity and selection criteria, Landerl and Moll (2010) conclude that comorbidities are the result of a complex interplay between both general and disorder-specific aetiological factors. In this context, two disorders sharing disorder-specific factors (e.g., neural abnormalities in IPS, see above) would be reflected by increasing comorbidity rates with more stringent criteria, whereas two disorders both involving more general factors (e.g., intelligence) should manifest in decreasing comorbidity rates with more stringent cut-offs. Basically, such a conclusion was conceptualized in the work by Rubinsten and Henik (2009) and will be discussed in greater detail in the following.

\subsection{Different Origins of Comorbidity}

In their theoretical article Rubinsten and Henik (2009) proposed three different frameworks within which dyscalculia and its comorbidities with other developmental disorders can be conceptualized. The first framework assumes a unique pathophysiology in the IPS to underlie developmental dyscalculia - a notion similar to that described above as the core deficit hypothesis. In the second framework, different symptomatologies at the cognitive level are attributed to different pathophysiologies, depicting a more multi-componential view of numerical cognition with the possibility of more specific impairments as advocated above. Finally, in their third framework, comorbidity is addressed. As already reflected by the differences between the first two frameworks, Rubinsten and Henik (2009) suggest both the possibility of comorbidities being caused by a single pathophysiology as well as being attributable to differing underlying pathologies (see Rubinsten and Henik 2009, Figure 2, p. 95). These conceptualizations of comorbidities with developmental dyscalculia are corroborated by the findings of Landerl and Moll (2010), as the latter provide first evidence that comorbidities may have different origins.

In this context, it is also important to note that the discussion about the origins and the conceptualization of comorbidities is not limited to developmental dyscalculia. Rather, there is currently an ongoing debate questioning the prevailing view of comorbidity representing the correlation of two latent variables (i.e., the co-occurring developmental disorders). As an alternative approach, Cramer et al. (2010, p. 137) suggest to conceptualize comorbidity as a network in which comorbidity is assumed to "arise from direct relations between symptoms of multiple disorders". Thereby, the co-occurrence of two or more disorders is not qualified 
by the correlation of latent variables defined by different observed variables which vary across studies (as employed tests or experimental set-ups vary). Instead, comorbidity arises at the level of the observed variables as overlapping and thereby directly related symptoms. Following this approach, it should be possible to differentiate between symptoms that are related to both comorbid disorders - thereby establishing their co-occurrence - and other symptoms, which are primarily related to only one of the disorders. While the former is less relevant for diagnostic purposes, identification of the latter would be extremely beneficial for the improvement of diagnostic validity and reliability.

However, research employing this rationale is only in its infancy and we are still lacking a universally agreed definition of developmental dyscalculia as well as standards for diagnosing it. With regard to comorbidities, this means that their evaluation should take into account variables such as selection criteria, preselection of samples, but also differences in the theoretical conceptualization of comorbidity. In this context, knowledge on whether an observed comorbidity rate is higher than expected by chance - on the basis of the prevalence of the single disordersprovides the researcher as well as the diagnostician with important additional information for evaluating its relevance. Therefore, we chose to recapitulate in the following on the issue of how co-occurrence rate expected by chance can be estimated.

\subsection{Comorbidity or Only Random Co-occurrence?}

Generally, estimating the comorbidity of two independent disorders as expected by chance is a rather simple matter of probability calculus. For instance, consider the prevalence of developmental dyscalculia to be about $8 \%$ of the population (see above) and that of developmental dyslexia to be about $10 \%$ (e.g., Lindergren et al. 1985; Lyytinen et al. 2004; Lam et al. 2008). Under the presupposition that the two disorders are independent of each other, that is, that suffering from one of these two does not influence the probability of suffering from the other one, the comorbidity expected by chance can be computed by multiplying the prevalence rates of the two disorders:

$$
p_{\text {comorbid }}=p(\text { Disorder } 1)^{*} p(\text { Disorder } 2)=p(\text { Disorder } 1 \mid \text { Disorder } 2)
$$

Thereby, for above given prevalence rates of developmental dyscalculia and dyslexia a random comorbidity rate of $.08 * .10=.008$ or $0.8 \%$ can be expected. Any association between these two disorders observed to be higher than this should consequently be considered to indicate epidemiological comorbidity in the sense that the two disorders are not statistically independent but seem to co-occur more frequently than expected by chance. This way, the product of the prevalence rates of two disorders always indicates the lower boundary of epidemiological comorbidity. 
Only when the co-occurrence of two disorders is more probable than expected by chance, it should be taken as evidence for an association of these two disorders.

However, as above introduced formula is based on the prevalence rates of the disorders of interest, estimating the random comorbidity of two disorders of which one is developmental dyscalculia is subject to problems already discussed above. As there is no generally agreed diagnostic criterion of developmental dyscalculia prevalence rates are highly dependent on the cut-off criteria used to diagnose dyscalculia. In turn, also the estimated random comorbidity changes with different cut-off criteria. For instance, when a cut-off criterion indexing the lower 5\% of the population to suffer from dyscalculia is used, basically, a prevalence rate of $5 \%$ is assumed. Following above described formula the random comorbidity of dyscalculia and dyslexia would be $.05 * .10=.005$ or $0.5 \%$ when relying on a prevalence rate of $10 \%$ for dyslexia as has been reported in the literature. Nevertheless, often much more liberal criteria are used for diagnosing both developmental dyscalculia as well as dyslexia, for instance cut-off criteria assuming all children falling $\leq 25$ th percentile to be either dyscalculic or dyslexic (see above). Taking into account the resulting prevalence rates of $25 \%$ for both disorders the comorbidity as estimated by chance raises to $.25 * .25=.0625$ or $6.25 \%$. And only if the actual comorbidity estimate is higher than this estimation, it is valid to assume a common underlying origin. Please note that this problem of inflated random comorbidity is even more aggravated when relying on selected samples such as samples from special schools or special education centers. For example Norman and Zigmond (1980) reported that in a sample of children diagnosed and served as learning disabled up to $62 \%$ of the children diagnosed with developmental dyscalculia also fulfilled the criteria for dyslexia. With a prevalence rate of $21 \%$ for developmental dyscalculia and $36 \%$ for dyslexia random comorbidity in this sample would be as high as $7.6 \%$. To further illustrate this point imagine a special education centre in which $70 \%$ of the children suffer from developmental dyscalculia and $80 \%$ suffer from developmental dyslexia in this case a comorbidity rate of $56 \%$ should be observed by chance. Taken together, we suggest that, as already argued above, it is important to take into account issues of selection criteria, sample preselection, and random comorbidity when interested in epidemiological comorbidity rates of developmental disorders. Preferentially, estimates of epidemiological comorbidity should be based on diagnoses following generally agreed criteria, evaluating performance in an unselected sample and testing against random comorbidity of the two disorders.

Nevertheless, research over the last years has not only led to the development of diagnostic criteria and diagnostic instruments as discussed above but also to a growing number of intervention approaches for dyscalculia. While all of these still need to be evaluated and optimized, they represent a first step towards providing children with dyscalculia with the support they need and deserve. Upon considering that neuroscience-based dyscalculia research is in its infancy, it is not surprising to learn that neuro-cognitively based intervention studies on developmental dyscalculia are extremely scarce. As regards behavioural/cognitive intervention, recent studies showed the effectiveness of intervention programmes targeted at the core deficit of 
numerical quantity processing (Kaufmann et al. 2003, 2005; Krajewski et al. 2008). Moreover, a recent meta-analysis of different intervention programmes (primarily targeted at more general mathematics learning disabilities) provided first hints that training in the domain of basic skills seemed to be most effective (Dowker 2001; Kroesbergen and van Luit 2003). However, intervention studies targeted at developmental dyscalculia deficiencies other than the numerical quantity subtype are still very rare. In the following section, existing intervention studies and their implications will be discussed and evaluated.

\section{Interventions for Dyscalculia: Up to Now}

Dyscalculia has proven to be a rather stable impairment (Shalev et al. 2005), having implications into adulthood and possibly all of an affected person's life (cf. Parsons and Bynner 2005). In the course of this realization, a variety of treatment approaches for developmental dyscalculia has been developed: prevention programmes that aim at compensating arithmetic difficulties before they aggravate into dyscalculia; and intervention programmes that tackle the difficulties of children who suffer from developmental dyscalculia. Furthermore, some approaches have been designed that so far have only been tested on typically developing children and do not yet fit into either of the above two categories. In the following, these approaches will be referred to as trainings. To a certain degree, dyscalculic children can profit from prevention programmes (Fuchs and Fuchs 2001). However, the different deficiencies that can underlie dyscalculia call for a tailored intervention programme that can effectively be adapted to children with specific arithmetic difficulties as regards the basic numerical competencies described above. This was also emphasized by Dowker (2004), who recommended that intervention should be individualised and furthermore, should take place relatively early in development.

In this section, we will give an overview over some contemporary treatment approaches, focussing on those addressing children in kindergarten or elementary school (see Table 2). We would like to emphasize, however, that this overview does not claim to be exhaustive and should thus not be taken as a review of all existing literature.

To evaluate these approaches, we propose three important criteria that an intervention/prevention programme should meet to successfully lead to long-lasting improvements in children with dyscalculia: First, because we assume that there are different deficiencies in dyscalculia based on impairments in different areas of basic numerical processing (see above), it would have to be multi-componential. It would thus have to involve different modules covering as many of the potentially impaired areas of basic numerical competencies as possible. Second, these modules should be applicable independently from one another, so that the training can be adapted to a child's specific needs and challenges. Thereby, redundant training of competencies that a child has already mastered can be avoided. The final criterion is for an intervention/prevention to be evaluated regarding its effectiveness for 


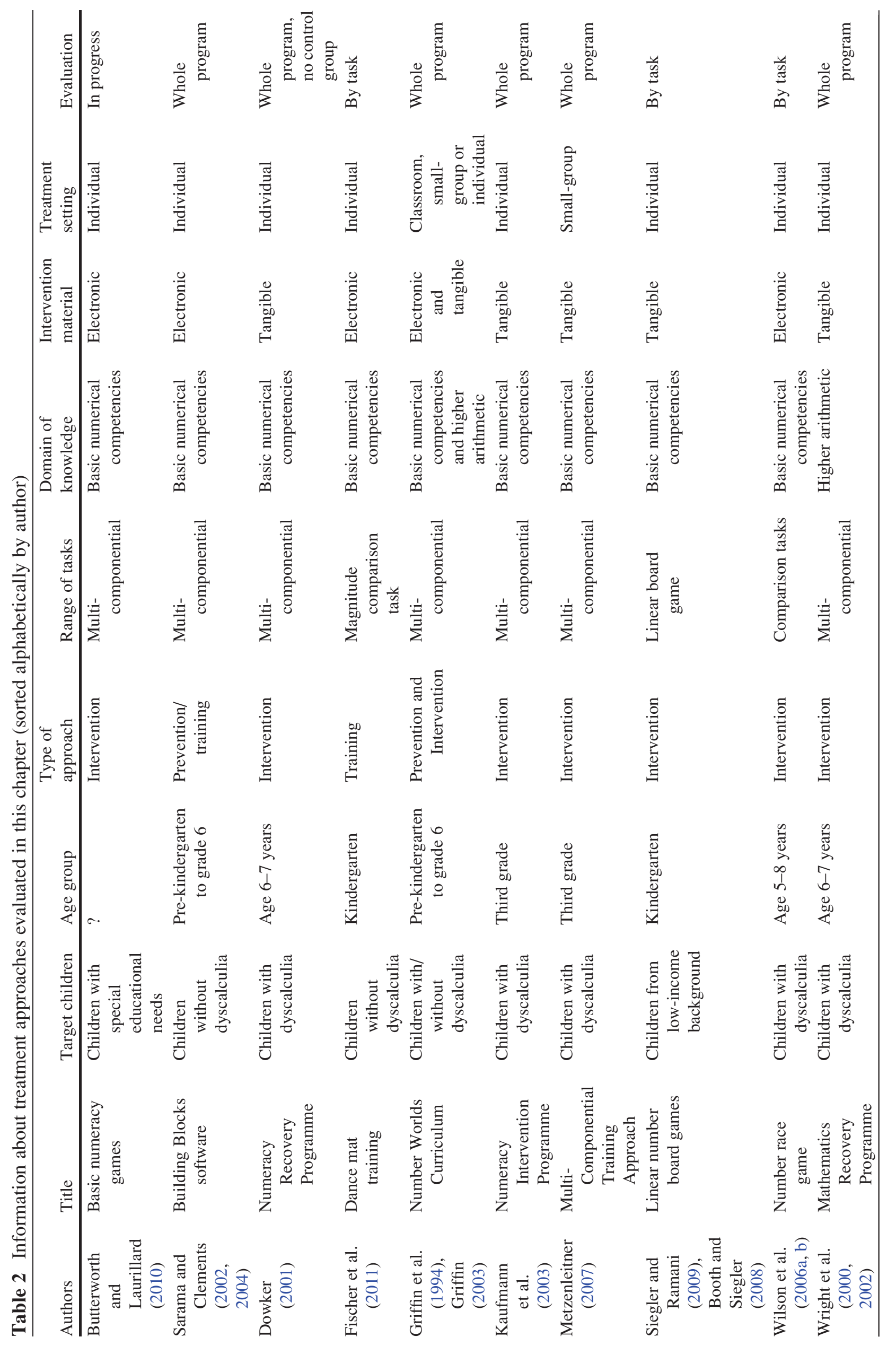


improving numerical performance of children with dyscalculia. Up to now, no treatment approach has been developed that fully meets all three of these criteria. Nevertheless, we would like to discuss a few promising approaches which have received growing interest over the last years.

Contemporary approaches at treating dyscalculia differ on several dimensions, such as the range of applied tasks, the domain of knowledge considered, intervention material, and whether they are designed for groups or individuals (see also Table 2 for an overview of the evaluated approaches and their characteristics). Accordingly, in the following section we will evaluate existent intervention/ prevention approaches with respect to these dimensions. In a concluding remark, we will then elaborate on what has so far been learned about the effectiveness of certain types of treatments.

\subsection{Range of Tasks: Multi-componential vs. Specific Approaches}

The majority of existing intervention approaches trains more than just one domain of numerical competence. Examples for multi-componential approaches are the Mathematics Recovery Programme by Wright and colleagues (Wright et al. 2000, 2002), which is based on a sequential model of numerical development; the Numeracy Recovery Programme by Dowker (2001) that trains numerous components of basic numerical processing; a Numeracy Intervention Programme by Kaufmann et al. (2003) focusing on basic numerical knowledge and conceptual knowledge; a Multi-Componential Training Approach for children with dyscalculia developed by the research group of Nuerk (e.g., Metzenleitner 2007; see also Müller 2010; Pircher 2007); the Building Blocks software (Sarama and Clements 2002, 2004), which provides an online-accessible mathematics curriculum and is based on research in a Logo programming environment (Clements 2002; see also Turtle Math; Clements and Meredith 1994); a new series of electronic Basic Numeracy Games (Butterworth and Laurillard 2010); and the probably most popular prevention and intervention programme for mathematics, the Number Worlds Curriculum by Griffin and colleagues (Griffin et al. 1994; Griffin 2003). These intervention programmes try to convey a large range of numerical competencies and knowledge so that children at a certain age level can improve in all age-relevant areas of arithmetic knowledge.

In contrast, some other programmes focus on training just one single competence which is then supposed to invoke improvement on other numerical capabilities and tasks as well. One such approach was developed by Siegler and colleagues (Siegler and Ramani 2009; Booth and Siegler 2008), who claim that improvement of children's mental number line accuracy (i.e., the accuracy of children's spatial representation of number magnitude, see above) induced by repeated playing of linear number board games should corroborate children's performance in tasks measuring other basic numerical competencies. Likewise, Fischer et al. (2011) tried to improve children's mental number line accuracy by training on a digital 
dance mat that enabled a bodily experience of the number line orientation. They found that the effects of this physical number line training generalized to transfer measures such as counting; thus speaking for a transfer of number line improvement onto other domains of numerical competence.

Considering the multi-componential vs. specific differentiation, the Number Race game by Wilson et al. (2006a, b) falls somewhere between the extremes as it was designed to train the number sense, which the authors describe as a basic understanding of quantities. However, although the number sense can be interpreted as one area of arithmetic proficiency, it involves several relevant components. Therefore, the game trains a number of different numerical comparison tasks, such as comparison of two non-symbolic magnitudes or comparison of the results of two simple addition problems. Again, this rather specific training impacted on other areas of arithmetic performance that were not explicitly trained (e.g., subtraction).

Taken together, there are advantages to both multi-componential as well as specific intervention programmes. To make an intervention programme interesting and beneficial for a wide range of audiences, multi-componential approaches have the advantage of being capable of specifically addressing different problems. However, a common drawback of multi-componential programmes is that to date most of them are only evaluated as a whole. Thereby, no conclusions can be drawn about whether the single elements of a programme are effective by themselves. In contrast, specific intervention approaches allow for a more accurate evaluation of their effectiveness. Additionally, when the trained task is actually essential for numerical proficiency in general, transfer effects into other domains of numerical abilities may be attained. Unfortunately, by means of such specific intervention programmes it is not possible to adapt the intervention to a certain child's needs covering all her/his specific problematic areas. However, such an adaptation would become necessary when - as we proposed - there are different deficiencies in dyscalculia (see Sect. 2 of this chapter) that call for different types of intervention.

\subsection{Domain of Knowledge: Basic Numerical Competencies vs. Arithmetic Procedures}

Considering the domain of numerical competencies trained there are important differences between intervention programmes. They either train basic numerical competencies or arithmetic procedures and tasks that are often based on curricular requirements. Some multi-componential approaches incorporate elements and tasks tapping both domains of knowledge (such as the Number Worlds Curriculum, the Building Blocks software, the Mathematics Recovery Programme, and the Numeracy Recovery Programme), while others address a range of basic numerical processing tasks (e.g., Butterworth and Laurillard 2010; Kaufmann et al. 2003; Metzenleitner 2007; and Wilson et al. 2006a, b). Approaches training only one specific area of arithmetic proficiency mainly focus on basic numerical competencies, because these 
are most likely to impact further arithmetic development and lead to significant improvements in other numerical domains. This is true for the above mentioned approaches by Siegler and Ramani (2009) as well as Fischer et al. (2011).

As we will elaborate on later in this section, basic numerical competencies are assumed to have to be mastered before a training of more elaborate arithmetic procedures can bring about lasting effects. Therefore, based on an extensive diagnostic examination, it seems usually advisable to start an intervention on the level of basic knowledge before administering training on more complex procedures. However, since children with mathematical difficulties often already lag behind their peers in school mathematics, topics currently discussed in class should also be addressed during intervention to avoid an increase of this performance gap and a resulting decrease in motivation. In sum, the everyday challenge in setting up the most appropriate intervention is to keep the balance between improving underlying basic numerical competencies and keeping track with school demands.

\subsection{Intervention Material: Tangible Games vs. Electronic Games}

For the most part, current intervention programmes attempt to impart numerical knowledge in a game-like and game-based fashion. This way, not only children's motivation is enhanced, but by visualizing concepts and making them accessible for children's own experience, greater learning effects can be achieved. For example, Metzenleitner (2007), Kaufmann and coworkers (2003, 2005), as well as Siegler and colleagues (Siegler and Ramani 2009; Booth and Siegler 2008) implemented tangible game material to improve children's performance, such as board and card games. Additionally, a lot of recent approaches utilize computers as an up-to-date, flexible, and motivating medium for interventions. The Number Race game (Wilson et al. 2006a, b), the Basic Numeracy Games (Butterworth and Laurillard 2010), the Building Blocks software (Sarama and Clements 2002, 2004), and the sensori-motor training by Fischer et al. (2011) convey numerical knowledge in an electronic game format. The Number Race game (Wilson et al. 2006a, b), the Basic Numeracy Games and the Building Blocks software (Sarama and Clements 2002, 2004) are also available online for download.

The benefits of computer-assisted intervention lie not only in their high motivational appeal but also the possibility to use multimedia (Mayer 1999, 2001), thereby allowing for a combination and integration of different presentational formats (i.e., text, graphics, animations, etc.). Additionally, computerized intervention can flexibly adapt to an individual learner's needs and skills, so that mainly tasks which need to be trained are presented. Due to these aspects, computer-assisted trainings can be very effective (Christensen and Gerber 1990; Räsänen et al. 2009). Nevertheless, when designed appropriately, tangible games also provide important benefits: They allow the use of haptic experience for children's knowledge acquisition. In this vein, children can manipulate objects in a real environment with their own hands, which has also been shown to improve performance through 
self-experience (Jonassen and Rohrer-Murphy 1999). A symbiosis of the two types of intervention material is attempted in the Number Worlds Curriculum (Griffin et al. 1994; Griffin 2003) that combines study workbooks, board games and other tangible intervention material with online games and a CD-Rom containing supporting material.

Another approach at a combination of technological elements with self-experience was attempted by Fischer et al. (2011). Their training required children to respond physically - with a full body movement on a digital dance mat - to a visually presented magnitude comparison task. These two approaches provide examples of how the benefits of the two types of intervention material can be joined - the high motivational appeal of electronic games and the physical self-experience of tangible games.

\subsection{Treatment Target: Groups vs. Individuals}

As regards the frequency of intervention programmes targeted at either individuals or groups, a clear gradient is observable. Of the approaches reviewed in this chapter, the majority is applied to individuals, only two to small groups (Kaufmann et al. 2003; Metzenleitner 2007), and only one was developed to be run in classroom settings (Griffin et al. 1994). Of course, interventions for developmental dyscalculia in classroom settings are hardly advisable. Children with average and high arithmetic proficiency would most probably be unchallenged, whereas the specific difficulties of children with dyscalculia could not be addressed appropriately (Kaufmann and Nuerk 2006). In such a setting, it is not possible to assure that all children understand a certain topic (Kroesbergen and Van Luit 2003), and some children with dyscalculia seem to be unresponsive to such forms of treatment (Fuchs and Fuchs 2001). However, prevention programmes (e.g., the prevention portion of the Number Worlds curriculum by Griffin and colleagues; Building Blocks, Sarama and Clements 2002, 2004) that comprise exercises at a medium level of difficulty can be administered successfully in classroom settings (Fuchs and Fuchs 2001). Thereby, the respective elements and tasks should not be too boring for good students but should at the same time prevent students with lower than average achievement from developing more serious math problems. Prevention programmes are, however, not sufficient to remedy difficulties of students already struggling with mathematics or exhibiting clear signs of developmental dyscalculia (Fuchs and Fuchs 2001). These children are much better cared for in individual interventions (Kaufmann and Nuerk 2006; Dowker 2004, 2009). Furthermore, an intervention tailored to a child's specific needs is also realized best in an individual setting where individual difficulties can be properly addressed and sessions can be adapted to the child's speed of progress (Kroesbergen and Van Luit 2003; Kaufmann and Nuerk 2006; Metzenleitner 2007).

Alternatively, interventions in small groups have advantages as well, mainly because they allow for social interaction. Be it a competitive or collaborative 
setting - working in a group can increase motivation drastically (Beirne-Smith 1991; Bientzle et al. 2009; Johnson and Johnson 1987; Slavin 1983; Webb 1989). Yet, what has to be considered in such a setting is how well children in a certain group fit together. Generally, members of a small group should start intervention at approximately the same level of proficiency, so that social comparison does not generate feelings of inferiority in individual children (Webb 1989).

\subsection{The Bottom Line on Existing Intervention Programmes}

Because of the huge diversity of existing intervention approaches, it is necessary to evaluate which types of trainings are most effective for which cohort of children. So far, one of the few meta-analyses on this topic was conducted by Kroesbergen and Van Luit (2003). They analyzed a total of 58 studies in which interventions were performed on kindergarten and elementary school children that were affected by what they termed mathematical difficulties. The authors defined an intervention as 'a specific instruction for a certain period to teach a particular (sub)domain of the mathematics curriculum'. In their analysis, Kroesbergen and van Luit (2003) distinguished between three domains of mathematical knowledge that are mastered at different levels of development. Their first and most basic domain is preparatory mathematics, which they described as the skill set that Dehaene (1997, 2001) termed the number sense. We suggest that despite slight differences in definition this domain also corresponds to the set of basic numerical competencies that we proposed in the first section of this chapter. The second domain, basic math skills (not to be confused with the above basic numerical competencies), builds upon these preparatory skills. Basic math skills involve the acquisition as well as automatization of the four basic mathematical operations (i.e., addition, subtraction, multiplication, and division). Finally, Kroesbergen and van Luit termed the third domain mathematical problem-solving skills. These are thought to play an important role in the solving of problems by applying previously acquired information. According to Kroesbergen and Van Luit (2003), the majority of intervention studies trained basic mathematical skills (e.g., multiplication), and training of these skills produced higher effect sizes than training of the other two domains (preparatory and problem solving skills). Furthermore, their analysis revealed that effect sizes increased with the age of the trained children. Surprisingly, duration of intervention and total intervention time correlated negatively with effect sizes. As a possible explanation, they hypothesized that short interventions might only train one very specific area of mathematics that is thus taught and learned more thoroughly.

From their meta-analysis, Kroesbergen and Van Luit (2003) drew a number of conclusions. First of all, they emphasized once again the choice of the most appropriate teaching method for a particular intervention. For example, interventions using direct instruction proved to be most effective when training basic math skills. Second, their analysis revealed that, while the use of computer-assisted instruction might be helpful to motivate students, it does not alone suffice to remediate children's 
basic difficulties. The full potential of computer-assisted instruction is only unfolded when combined with direct instructions from a teacher. Finally, it seems that children with special needs do not particularly benefit from peer tutoring. Those children depend on instruction by an adult teacher who can better perceive and react to their individual needs.

In our opinion, the meta-analysis by Kroesbergen and Van Luit (2003) highlights a fairly prominent problem of current intervention programmes: Most of them set out at a level that, while termed by the authors as basic math skills, is in fact far from what would be called basic taking into account evidence from neuropsychological research (see Sect. 2 of the current chapter). At the bottom of mathematics proficiency is what they refer to as preparatory mathematics, which are in our view not just preparatory, but essential for any type of numerical and mathematical knowledge acquisition. We thus prefer the terminology we introduced earlier in the chapter, naming them basic numerical competencies. Because recent neurocognitive research suggests deficits of dyscalculic children in such basic numerical competencies (see above), we propose that they should receive more attention in future intervention programmes.

Certainly, the meta-analysis of Kroesbergen and Van Luit (2003) provides pointers as to what a successful intervention for dyscalculia should or should not encompass. We would like to emphasize, however, that prior to any intervention, appropriate diagnostics are required to not only identify children with dyscalculia as such, but also describe their specific impairments properly to allow for a tailored intervention. Furthermore, awareness of the existence of this learning disorder should be increased in teaching professionals as well as parents, so that children with dyscalculia are no longer stigmatized and can receive appropriate support to help them take on their mathematical difficulties. An exemplary step in this direction has been taken in the UK, where the Every Child a Chance charity in partnership with the government has begun to develop the Every Child Counts programme (see Dowker 2009, for a description). This programme aims to support children with mathematical difficulties all over the country by trained teachers that apply an intervention approach called Numbers Count. This intervention approach covers a wide range of areas of number processing and mathematics, and therefore seems particularly promising at prevention and remediation of developmental dyscalculia. The programme is currently in its first year of implementation and its progress can be followed at http://www.edgehill.ac.uk/everychildcounts/. In our opinion, the Every Child Counts programme proves that intervention for dyscalculia can be provided and implemented nation-wide, thereby raising awareness and nurturing research on the topic.

Recapitulating the body of work we considered in this section, we have not yet come upon an existing intervention that meets all three of the criteria we proposed above (see introduction to Sect. 5): (i) an intervention programme should be multicomponential, (ii) adaptable to a child's special needs, and (iii) evaluated regarding its effectiveness for improving arithmetic performance of children with dyscalculia. Currently, there is a large number of broad approaches that, while often covering several areas of mathematical knowledge, were only evaluated as a whole, with no 
information provided on how efficient single modules are or why they were included in the first place. Moreover, when looking at the tasks involved in most intervention programmes, it seems that results from neurocognitive research are often more or less neglected. The great majority of interventions focuses on training arithmetic operations, with training content being based on curricular requirements. However, a long line of research indicates now that to understand arithmetic operations and successfully manipulate numbers, it is inevitably necessary to have a proper basic numerical foundation to build on (see above; e.g., Dehaene 2009; Holloway and Ansari 2009). Even the most basic arithmetic operations build on even more basic numerical representations and competencies such as the ones introduced above (e.g., McCrink and Spelke 2010; McCrink and Wynn 2004, 2007). Thus, a tailored, theory-grounded training programme should first of all examine how well such basic numerical competencies are developed in a dyscalculic child before training arithmetic operations and facts that build on them, thereby ensuring that children can master and understand complex arithmetic in their later educational career.

To sum up the current section on existing interventions, we claim that there is still the need for a thoroughly evaluated, neuropsychologically grounded multicomponential intervention programme fulfilling all three of the above criteria. However, a couple of interesting trainings have already been developed that could viably contribute to such a programme.

\section{Conclusion}

In this chapter, we discussed a number of issues regarding developmental dyscalculia that we find particularly important. We thereby went from a definition of its symptoms to diagnostic measures and possible comorbidities and finally, to intervention and training approaches. As a starting point, we emphasized that for a reliable diagnosis of dyscalculia, the distinction between different dyscalculia deficiencies may be beneficial. Such an identification of specific numerical deficits can be helpful for the design and choice of intervention measures. To identify specific deficits we argue that it is necessary to apply diagnostic measures that enable a distinction between them. This, however, is not the only challenge in diagnosing dyscalculia. As there is still no general consensus as to what criteria should be met for a diagnosis, we proposed a solution to this issue that should work for an initial diagnosis as well as the choice of specific intervention (see Table 1). By applying these cut-off criteria, the sensitivity of diagnostic measures may be improved and an individualized intervention can thereby be provided to all children in need of it.

In the course of diagnostics, it is also important to consider possible comorbidities. Although a lot of research has been dedicated to the co-occurrence of dyscalculia with other developmental disorders, this research has not yet provided consistent results. The problem of increasing comorbidity rates for more liberal as 
well as for stricter cut-off criteria and the problem of participant selection in such studies are only some of the future challenges. Additionally, we emphasized that it is important to consider the percentage of comorbidity of two developmental disorders expected by chance, especially when working with preselected samples.

Finally, once a diagnosis is made, it is important to choose an intervention. We gave an overview of existing remediation approaches for developmental dyscalculia and/or mathematics learning disabilities. Although we may have criticised all of them in one regard or the other, this is not to say that one should not apply them. Indeed, all of the approaches we reviewed train important numerical competencies and may therefore be beneficial for children with dyscalculia. Of course, one has to be careful in choosing the right intervention for a certain child, so as to adapt to its individual needs and challenges.

Coming back to the introduction of this chapter, we would like to emphasize that research interest on dyscalculia is slowly, but nevertheless steadily, growing (see Fig. 1). This is encouraging in several ways as it might induce that (i) diagnostic as well as intervention measures are developed, evaluated, and improved continuously; and (ii) that awareness is raised so that we now know a lot more about developmental dyscalculia than we did just 20 years ago. Even though extensive support for children with developmental dyscalculia is indeed needed, we are on a promising way, as indicated by the example of the Every Child Counts programme in the UK. Generally, we agree with Butterworth and Laurillard (2010) that both the research and teaching community need to work hand in hand to provide successful intervention for every child affected by mathematical difficulties. Furthermore, we are confident that this may be an attainable goal that we are on the right track to achieving.

Acknowledgements This research was funded in part by the German Research Foundation (DFG) by means of a project within the Research Group (Forschergruppe) Analyse und Förderung effektiver Lehr-Lern-Prozesse (FOR 738/2/TP02) granted to Ulrike Cress and Hans-Christoph Nuerk supporting Korbinian Moeller. Additionally, part of this research was supported by a project in the ScienceCampus (WissenschaftsCampus) Tuebingen (Cluster 1/TP 1).

\section{References}

American Psychiatric Association. (2000). Diagnostic and statistical manual of mental disorders DSM-IV-TR (4th ed., Text Rev.). Washington, DC: American Psychiatric Publication.

Amthauer, R., Brocke, B., Liepmann, D., \& Beauducel, A. (2001). Intelligenz-Struktur-Test 2000 $R(I-S-T 2000$ R) - Handanweisung. Göttingen: Hogrefe.

Ashcraft, M. H. (1987). Children's knowledge of simple arithmetic: A developmental model and simulation. In R. Brainerd \& J. Bisanz (Eds.), Formal methods in developmental research (pp. 302-338). New York: Springer.

Ashkenazi, S., \& Henik, A. (2010). A disassociation between physical and mental number bisection in developmental dyscalculia. Neuropsychologia, 48, 2861-2868.

Ashkenazi, S., Henik, A., Ifergane, G., \& Shelet, I. (2008). Basic numerical processing in left intraparietal sulcus (IPS) acalculia. Cortex, 44, 439-448. 
Auerbach, J. G., Gross-Tsur, V., Manor, O., \& Shalev, R. S. (2008). Emotional and behavioral characteristics over a six-year period in youths with persistent and nonpersistent dyscalculia. Journal of Learning Disabilities, 41, 263-273.

Bachot, J., Gevers, W., Fias, W., \& Roeyers, H. (2005). Number sense in children with visuospatial disabilities: Orientation of the mental number line. Psychology Science, 47, 172-183.

Badian, N. A. (1983). Dyscalculia and nonverbal disorders of learning. In H. R. Myklebust (Ed.), Progress in learning disabilities (Vol. 5, pp. 235-264). New York: Stratton.

Barbaresi, W. J., Katusic, S., Colligan, R. C., Weaver, A. L., \& Jacobsen, S. J. (2005). Math learning disorder: Incidence in a population-based birth cohort, 1976-82, Rochester, Minn. Ambulatory Pediatrics, 5, 281-289.

Beirne-Smith, M. (1991). Peer tutoring in arithmetic for children with learning disabilities. Exceptional Children, 57, 330-337.

Berch, D. B., Foley, E. J., Hill, R. J., \& McDonough Ryan, P. (1999). Extracting parity and magnitude from Arabic numerals: Developmental changes in number processing and mental representation. Journal of Experimental Psychology, 74, 286-308.

Bientzle, M., Wodzicki, K., Lingnau, A., \& Cress, U. (2009). Enhancing pair learning of pupils with cognitive disabilities: Structural support with help of floor control. International Conference on Computer Supported Collaborative Learning (CSCL), Rhodes, Greece.

Booth, J. L., \& Siegler, R. S. (2008). Numerical magnitude representations influence arithmetic learning. Child Development, 79, 1016-1031.

Brown, V., Cronin, M., \& McEntire, E. (1994). Test of mathematical abilities (TOMA-2). Austin: Pro-Ed.

Burbaud, P., Camus, O., Guehl, D., Bioulac, B., Caille, J.-M., \& Allard, M. (2000). Influence of cognitive strategies on the pattern of cortical activation during mental subtraction: A functional imaging study in human subjects. Neuroscience Letters, 287, 76-80.

Butterworth, B. (1999). The mathematical brain. London: Macmillan.

Butterworth, B. (2003). Dyscalculia screener. London: nferNelson Publishing Company Limited.

Butterworth, B. (2005). The development of arithmetical abilities. Journal of Child Psychology and Psychiatry, 46, 3-18.

Butterworth, B., \& Laurillard, D. (2010). Low numeracy and dyscalculia: Identification and intervention. ZDM Mathematics Education, 42, 527-539.

Bynner, J., \& Parsons, S. (1997). Does numeracy matter? Evidence from the National Child Development Study on the impact of poor numeracy on adult life. London: Basic Skills Agency.

Campbell, J. I. D. (1995). Mechanisms of simple addition and multiplication: A modified networkinterference theory and simulation. Mathematical Cognition, 1, 121-165.

Consensus project sponsored by the international dyslexia association. (2002). The national institutes of child health and human development.

Christensen, C. A., \& Gerber, M. M. (1990). Effectiveness of computerized drill and practice games in teaching basic math facts. Exceptionality, 1, 149-165.

Claros-Salinas, D., Nuerk, H.-C., \& Willmes, K. (2009). Störungen der Zahlenverarbeitung. In W. Sturm, M. Hermann, \& T. Münte (Eds.), Lehrbuch der klinischen Neuropsychologie: Grundlagen, Methoden, Diagnostik, Therapie. Heidelberg: Spektrum-Verlag.

Clements, D. H. (2002). Computers in early childhood mathematics. Contemporary Issues in Early Childhood, 3, 10-181.

Clements, D. H., \& Meredith, J. S. (1994). Turtle math [Computer program]. Montreal: Logo Computer Systems, Inc.

Cohen, L., \& Dehaene, S. (2000). Calculating without reading: Unsuspected residual abilities in pure alexia. Cognitive Neuropsychology, 17, 563-583.

Cohen Kadosh, R., Cohen Kadosh, K., Kaas, A., Henik, A., \& Goebel, R. (2007). Notationdependent and- independent representations of numbers in the parietal lobes. Neuron, 53, $165-167$.

Cramer, A. O., Waldorp, L. J., van der Maas, H. L., \& Borsboom, D. (2010). Comorbidity: A network perspective. The Behavioral and Brain Sciences, 33, 137-150. 
de Hevia, M. D., \& Spelke, E. S. (2009). Spontaneous mapping of number and space in adults and young children. Cognition, 110, 198-207.

de Hevia, M. D., \& Spelke, E. S. (2010). Number-space mapping in human infants. Psychological Science, 21, 653-660.

Dehaene, S. (1997). The number sense: How the mind creates mathematics. New York: Oxford University Press.

Dehaene, S. (2001). Précis of the number sense. Mind and Language, 16, 16-36.

Dehaene, S. (2009). Origins of mathematical intuitions: The case of arithmetic. Annals of the New York Academy of Sciences, 1156, 232-259.

Dehaene, S., \& Cohen, L. (1995). Towards an anatomical and functional model of number processing. Mathematical Cognition, 1, 83-120.

Dehaene, S., \& Cohen, L. (1997). Cerebral pathways for calculation: Double dissociation between rote verbal and quantitative knowledge of arithmetic. Cortex, 33, 219-250.

Dehaene, S., Bossini, S., \& Giraux, P. (1993). The mental representation of parity and number magnitude. Journal of Experimental Psychology. General, 122, 371-396.

Dehaene, S., Piazza, M., Pinel, P., \& Cohen, L. (2003). Three parietal circuits for number processing. Cognitive Neuropsychology, 20, 487-506.

Delazer, M., Domahs, F., Bartha, L., Brenneis, C., Lochy, A., Trieb, T., \& Benke, T. (2003). Learning complex arithmetic - An fMRI study. Cognitive Brain Research, 18, 76-88.

Delazer, M., Ischebeck, A., Domahs, F., Zamarian, L., Koppelstaetter, F., Siedentopf, C. M., Kaufmann, L., Benke, T., \& Felber, S. (2005). Learning by strategies and learning by drill Evidence from an fMRI study. Neurolmage, 25, 838-849.

Dirks, E., Spyer, G., van Lieshout, E., \& de Sonneville, L. (2008). Prevalence of combined reading and arithmetic disabilities. Journal of Learning Disabilities, 41, 460-473.

Domahs, F., Krinzinger, H., \& Willmes, K. (2008). Mind the gap between both hands: Evidence for internal finger-based number representations in children's mental calculation. Cortex, 44, 359-367.

Domahs, F., Moeller, K., Huber, S., Willmes, K., \& Nuerk, H.-C. (2010). Embodied numerosity: Implicit hand-based representations influence symbolic number processing across cultures. Cognition, 116, 251-266.

Dowker, A. (2001). Numeracy recovery: A pilot scheme for early intervention with young children with numeracy difficulties. Support for Learning, 16, 6-10.

Dowker, A. (2004). What works for children with mathematical difficulties? London: Department for Education and Skills.

Dowker, A. (2005). Individual differences in arithmetic: Implications for psychology, neuroscience and education. Hove: Psychology Press.

Dowker, A. (2009). What works for children with mathematical difficulties? The effectiveness of intervention schemes. London: Department for Children, Schools and Families.

Eye, A. V., \& Bogat, G. A. (2006). Person-oriented and variable-oriented research: Concepts, results, and development. Merrill-Palmer Quarterly, 52, 390-420.

Fischer, M. H. (2008). Finger counting habits modulate spatial-numerical associations. Cortex, 44, 386-392.

Fischer, U., Moeller, K., Bientzle, M., Cress, U., \& Nuerk, H.-C. (2011). Sensori-motor spatial training of number magnitude representation. Psychonomic Bulletin \& Review, 18(1), 177-183.

Fletcher, J. M., Francis, D. J., Shaywitz, S. E., Lyon, G. R., Foorman, B. R., Stuebing, K. K., \& Shaywitz, B. A. (1998). Intelligent testing and the discrepancy model for children with learning disabilities. Learning Disabilities Research and Practice, 13, 186-203.

Fuchs, L. S., \& Fuchs, D. (2001). Principles for the prevention and intervention of mathematics difficulties. Learning Disabilities Research and Practice, 16, 85-95.

Fuchs, L. S., Compton, D. L., Fuchs, D., Paulsen, K., Bryant, J. D., \& Hamlett, C. L. (2005). The prevention, identification, and cognitive determinants of math difficulty. Journal of Educational Psychology, 97, 493-513. 
Galton, F. (1880). Visualized numerals. Nature, 22, 494-495.

Ganor-Stern, D., Pinhas, M., \& Tzelgov, J. (2009). Comparing two-digit numbers: The importance of being presented together. The Quarterly Journal of Experimental Psychology, 62, 444-452.

Geary, D. C. (1993). Mathematical disabilities: Cognitive, neuropsychological, and genetic components. Psychological Bulletin, 114, 345-362.

Geary, D. C. (2004). Mathematics and learning disabilities. Journal of Learning Disabilities, $37,4-15$.

Geary, D. C., Hamson, C. O., \& Hoard, M. K. (2000). Numerical and arithmetical cognition: A longitudinal study of process and concept deficits in children with learning disabilities. Journal of Experimental Child Psychology, 77, 236-263.

Geary, D. C., Hoard, M. K., Byrd-Craven, J., Nugent, L., \& Numtee, C. (2007). Cognitive mechanisms underlying achievement deficits in children with mathematical learning disability. Child Development, 78, 1343-1359.

Geary, D. C., Hoard, M. K., Nugent, L., \& Byrd-Craven, J. (2008). Development of number line representation in children with mathematical learning disability. Developmental Neuropsychology, 3, 277-299.

Gebuis, T., Cohen Kadosh, R., de Haan, E., \& Henik, A. (2009). Automatic quantity processing in 5-year olds and adults. Cognitive Processing, 10, 133-142.

Gersten, R., \& Chard, D. (1999). Number sense: Rethinking arithmetic instruction for students with mathematical disabilities. Journal of Special Education, 3, 18-29.

Ginsburg, H. P., \& Baroody, A. J. (2003). Test of early mathematics ability (3rd ed.). Austin: Pro-Ed, Incorporated.

Grabner, R. H., Ansari, D., Reishofer, G., Stern, E., Ebner, F., \& Neuper, C. (2007). Individual differences in mathematical competence predict parietal brain activation during mental calculation. NeuroImage, 38, 346-356.

Gracia-Bafalluy, M., \& Noël, M.-P. (2008). Does finger training increase young children's numerical performance? Cortex, 44, 368-375.

Griffin, S. (2003). Number Worlds: A research-based mathematics program for young children. In D. H. Clements \& A. DiBiase (Eds.), Engaging young children in mathematics: Findings of the 2000 national conference on standards for preschool and kindergarten mathematics education (pp. 325-342). Hillsdale: Erlbaum Associates, Inc.

Griffin, S., Case, R., \& Siegler, R. S. (1994). Rightstart: Providing the central conceptual prerequisites for first formal learning of arithmetic to students at risk for school failure. In K. McGilly (Ed.), Classroom lessons: Integrating cognitive theory and classroom practice (pp. 1-50). Cambridge, MA: MIT Press/Bradford Books.

Gross, J. (2009). The long term costs of numeracy difficulties. London: Every Child Chance Trust (KPMG).

Gross-Tsur, V., Manor, O., \& Shalev, R. S. (1996). Developmental dyscalculia: Prevalence and demographic features. Developmental Medicine and Child Neurology, 38, 25-33.

Helmreich, I., Zuber, J., Pixner, S., Kaufmann, L., Nuerk, H.-C., \& Moeller, K. (2011). Language effects on children's mental number line: How cross-cultural differences in number word systems affect spatial mappings of numbers in a non-verbal task. Journal of Cross-Cultural Psychology, 42(4), 598-613.

Holloway, I. D., \& Ansari, D. (2009). Mapping numerical magnitudes onto symbols: The numerical distance effect and individual differences in children's mathematics and achievement. Journal of Experimental Child Psychology, 103, 17-29.

Howell, R., Sidorenko, E., \& Jurica, J. (1987). The effects of computer use on the acquisition of multiplication facts by a student with learning disabilities. Journal of Learning Disabilities, 20, 336-341.

Hresko, W., Schlieve, P., Herron, S., Swain, C., \& Sherbenou, R. (2003). Comprehensive Mathematical Abilities Test (CMAT). Austin: PRO-ED.

Hubbard, E. M., Piazza, M., Pinel, P., \& Dehaene, S. (2005). Interactions between number and space in parietal cortex. Nature Reviews Neuroscience, 6, 435-448. 
Isaacs, E. B., Edmonds, C. J., Lucas, A., \& Gadian, D. G. (2001). Calculation difficulties in children of very low birthweight: A neural correlate. Brain, 124, 1701-1707.

Ischebeck, A., Zamarian, L., Siedentopf, C., Koppelstätter, F., Benke, T., Felber, S., \& Delazer, M. (2006). How specifically do we learn? Imaging the learning of multiplication and subtraction. NeuroImage, 30, 1365-1375.

Ischebeck, A., Zamarian, L., Schocke, M., \& Delazer, M. (2009). Flexible transfer of knowledge in mental arithmetic - An fMRI study. Neurolmage, 44, 1103-1112.

Johnson, D., \& Johnson, R. (1987). Cooperative, competitive, and individualistic learning. Journal of Research and Development in Education, 12, 8-15.

Jonassen, D. H., \& Rohrer-Murphy, L. (1999). Activity theory as a framework for designing constructivist learning environments. Educational Technology Research and Development, 47, $61-79$.

Jordan, N. C., \& Montani, T. O. (1997). Cognitive arithmetic and problem solving: A comparison of children with specific and general mathematics difficulties. Journal of Learning Disabilities, 30, 624-634.

Jordan, N. C., Kaplan, D., \& Hanich, L. B. (2002). Achievement growth in children with learning difficulties in mathematics: Findings of a two-year longitudinal study. Journal of Educational Psychology, 96, 586-597.

Kaplan, B., Crawford, S., Cantell, M., Kooistra, L., \& Dewey, D. (2006). Comorbidity, cooccurrence, continuum: What's in a name? Child: Care, Health and Development, 32, 723-731.

Kaufman, A. S., \& Kaufman, N. L. (1983). Kaufman Assessment Battery for Children (K-ABC). Circle Pines: American Guidance Service.

Kaufmann, L., \& Nuerk, H.-C. (2005). Numerical development: Current issues and future perspectives. Psychology Science, 47, 142-170.

Kaufmann, L., \& Nuerk, H.-C. (2006). Die Entwicklung des Rechnens und dessen Störungen: Genese, Modelle, Diagnostik und Intervention. Zeitschrift für Legasthenie und Dyskalkulie $(B V L), 2,11-16$.

Kaufmann, L., \& Nuerk, H.-C. (2008). Basic number processing deficits in ADHD: A broad examination of elementary and complex number processing skills in 9- to 12-year-old children with ADHD-C. Developmental Science, 11, 692-699.

Kaufmann, L., Handl, P., \& Thöny, B. (2003). Evaluation of a numeracy intervention program focusing on basic numerical knowledge and conceptual knowledge: A pilot study. Journal of Learning Disabilities, 36, 564-573.

Kaufmann, L., Delazer, M., Pohl, R., Semenza, C., \& Dowker, A. (2005). Effects of a specific numeracy educational program in kindergarten children: A pilot study. Educational Research and Evaluation, 11, 405-431.

Kaufmann, L., Nuerk, H.-C., Graf, M., Delazer, M., \& Willmes, K. (2009a). TEDI-MATH: Test zur Erfassung numerisch-rechnerischer Fertigkeiten für 4-8 Jährige. Zürich: Hans-Huber-Verlag.

Kaufmann, L., Vogel, S. E., Starke, M., Kremser, C., \& Schocke, M. (2009b). Numerical and nonnumerical ordinality processing in children with and without developmental dyscalculia: Evidence from fMRI. Cognitive Development, 24, 486-494.

Kaufmann, L., Wood, G., Rubinsten, O., \& Henik, A. (2011). Meta-analysis of developmental fMRI studies investigating typical and atypical trajectories of number processing and calculation. Developmental Neuropsychology, 36(6), 763-787.

Klauer, K. J. (1992). In Mathematik mehr leistungsschwache Mädchen, im Lesen und Schreiben mehr leistungsschwache Jungen? Zur Diagnostik von Teilleistungsschwächen. Zeitschrift für Entwicklungspsychologie und Pädagogische Psychologie, 24, 48-65.

Klein, E., Moeller, K., Dressel, K., Domahs, F., Wood, G., Willmes, K., \& Nuerk, H.-C. (2010). To carry or not to carry - is this the question? Disentangling the carry effect in multi-digit addition. Acta Psychologica, 135, 67-76.

Koontz, K. L., \& Berch, D. B. (1996). Identifying simple numerical stimuli: Processing inefficiencies exhibited by arithmetic learning disabled children. Mathematical Cognition, 2, $1-23$.

Kosc, L. (1974). Developmental dyscalculia. Journal of Learning Disabilities, 7, 164-177. 
Koumoula, A., Tsironi, V., Stamouli, V., Bardani, I., Siapati, S., Graham-Pavlou, A., et al. (2004). An epidemiological study of number processing and mental calculation in Greek school children. Journal of Learning Disabilities, 37, 377-388.

Krajewski, K., Nieding, G., \& Schneider, W. (2008). Kurz- und langfristige Effekte mathematischer Frühförderung im Kindergarten durch das Programm "Mengen, zählen, Zahlen". Zeitschrift für Entwicklungspsychologie und Pädagogische Psychologie, 40, 135-146.

Kroesbergen, E. H., \& Van Luit, J. E. H. (2003). Mathematics interventions for children with special educational needs: A meta-analysis. Remedial and Special Education, 24, 97-114.

Kucian, K., Loenneker, T., Dietrich, T., Dosch, M., Martin, E., \& von Aster, M. (2006). Impaired neural networks for approximate calculation in dyscalculic children: A functional MRI study. Behavioral and Brain Functions, 2, 31.

Kucian, K., von Aster, M., Loenneker, T., Dietrich, T., \& Martin, E. (2008). Development of neural networks for exact and approximate calculation: An fMRI study. Developmental Neuropsychology, 33, 447-473.

Lam, F., McBride-Chang, C., Lam, C., Wong, S., Chow, S., \& Doo, S. (2008). Towards early identification of dyslexia in Chinese preschool children: A study on reading and cognitive profile in children with genetic risk of dyslexia in Hong Kong. Hong Kong Journal of Pediatrics, 13, 90-98.

Landerl, K., \& Kölle, C. (2009). Typical and atypical development of basic numerical skills. Journal of Experimental Child Psychology, 103, 546-565.

Landerl, K., \& Moll, K. (2010). Comorbidity of learning disorders: Prevalence and familial transmission. Journal of Child Psychology and Psychiatry, 51, 287-294.

Landerl, K., Bevan, A., \& Butterworth, B. (2004). Developmental dyscalculia and basic numerical capacities: A study of 8-9-year-old students. Cognition, 93(2), 99-125.

Lewis, C., Hitch, G. J., \& Walker, P. (1994). The prevalence of specific arithmetic difficulties and specific reading difficulties in 9- to 10-year-old boys and girls. Journal of Child Psychology and Psychiatry, 35, 283-292.

Lindemann, O., Alipour, A., \& Fischer, M. H. (2011). Finger counting habits in middle-eastern and western individuals: An online survey. Journal of Cross-Cultural Psychology., 42, 566-578.

Lindergren, S., De Renzi, E., \& Richman, L. (1985). Cross-national comparisons of developmental dyslexia in Italy and the United States. Child Development, 56, 1404-1417.

Lyytinen, H., Aro, M., \& Holopainen, L. (2004). Dyslexia in Finland. In I. Smythe, J. Everatt, \& R. Salter (Eds.), International book of dyslexia: A guide to practical and resources (pp. 92-95). London: Wiley.

Macizo, P., \& Herrera, A. (2010). Two-digit number comparison: Decade-unit and unit-decade produce the same compatibility effect with number words. Canadian Journal of Experimental Psychology, 64, 17-24.

Mann, A., Moeller, K., Pixner, S., Kaufmann, L., \& Nuerk, H.-C. (2011). Attentional strategies in place-value integration: A longitudinal study on two-digit number comparison. Zeitschrift für Psychologie/Journal of Psychology, 219, 42-49.

Marx, P., Weber, J. M., \& Scchneider, W. (2001). Leghastenie versus allgemeine LeseRechtschreibschwäche. Zeitschrift für Pädagogische Psychologie, 15, 85-98.

Mayer, R. E. (1999). Designing instruction for constructivist learning. In C. M. Reigeluth (Ed.), Instructional-design theories and models: Vol. II. A new paradigm of instructional theory (pp. 141-159). Mahwah: Lawrence Erlbaum.

Mayer, R. E. (2001). Multimedia learning. Cambridge: Cambridge University Press.

Mazzocco, M. M., \& Myers, G. F. (2003). Complexities in identifying and defining mathematics learning disabilities in the primary school-age years. Annals of Dyslexia, 53, 218-253.

McCloskey, M., \& Lindemann, M. (1992). Mathnet: Preliminary results from a distributed model of arithmetic fact retrieval. In J. I. Campbell (Ed.), The nature and origins of mathematical skills (pp. 365-409). Amsterdam: North Holland/Elsevier.

McCrink, K., \& Spelke, E. S. (2010). Core multiplication in childhood. Cognition, 116, 204-216.

McCrink, K., \& Wynn, K. (2004). Large-number addition and subtraction by 9-month-old infants. Psychological Science, 15, 776-781. 
McCrink, K., \& Wynn, K. (2007). Ratio abstraction by 6-month-old infants. Psychological Science, $18,740-745$.

McCrink, K., \& Wynn, K. (2009). Operational momentum in large-number addition and subtraction by 9-months-old. Journal of Experimental Child Psychology, 103, 400-408.

McLean, J. F., \& Hitch, G. J. (1999). Working memory impairments in children with specific arithmetic learning difficulties. Journal of Experimental Child Psychology, 74, 240-260.

Metzenleitner, N. (2007). Wirksamkeit eines multikomponentiellen Interventionsprogramms für rechenschwache Kinder in Bezug auf semantische und räumliche Größenrepräsentation. Unpublished diploma's thesis, University of Salzburg, Salzburg.

Miller, E. K. (2000). The prefrontal cortex and cognitive control. Nature Reviews Neuroscience, $1,58-65$.

Miura, I. T., Okamoto, Y., Kim, C. C., Steere, M., \& Fayol, M. (1993). First graders' cognitive representation of number and understanding of place value: Cross-national comparisons France, Japan, Korea, Sweden, and the United States. Journal of Educational Psychology, $85,24-30$.

Miura, I. T., Okamoto, Y., Kim, C. C., Chang, C.-M., Steere, M., \& Fayol, M. (1994). Comparisons of children's cognitive representation of number: China, France, Japan, Korea, Sweden and the United States. International Journal of Behavioral Development, 17, 401-411.

Moeller, K., \& Nuerk, H.-C. (2009, January). On the cognitive instantiation of the carry operation in addition. Evidence from eye-tracking. Poster presented at the 27th European Workshop of Cognitive Neuropsychology, Bressanone, Italy, 25-30 January 2008.

Moeller, K., Pixner, S., Klein, E., Cress, U., \& Nuerk, H.-C. (2009a). Zahlenverarbeitung ist nicht gleich Rechnen - Eine Beschreibung basisnumerischer Repräsentationen und spezifischer Interventionsansätze. Prävention und Rehabilitation, 21, 121-136.

Moeller, K., Neuburger, S., Kaufmann, L., Landerl, K., \& Nuerk, H.-C. (2009b). Basic number processing in developmental dyscalculia: Evidence from eye tracking. Cognitive Development, 24, 371-386.

Moeller, K., Pixner, S., Kaufmann, L., \& Nuerk, H.-C. (2009c). Children's early mental number line: Logarithmic or rather decomposed linear? Journal of Experimental Child Psychology, $103,503-515$.

Moeller, K., Klein, E., \& Nuerk, H.-C. (2011a). (No) small adults - Children's processing of carry addition problems. Developmental Neuropsychology, 36, 702-720.

Moeller, K., Klein, E., \& Nuerk, H.-C. (2011b). Three processes underlying the carry effect in addition - Evidence from eye-tracking. British Journal of Psychology, 102, 623-645.

Molko, N., Cachia, A., Riviere, D., Mangin, J. F., Bruandet, M., Le Bihan, D., et al. (2003). Functional and structural alterations of the intraparietal sulcus in a developmental dyscalculia of genetic origin. Neuron, 40, 847-858.

Müller, S. (2010). Wirksamkeit eines multikomponentiellen Interventionsprogramms bei rechenschwachen Kindern in Bezug auf das Rechnen und das Verständnis des Basis-10 Systems. Unpublished diploma's thesis, University of Salzburg, Salzburg.

Murphy, M. M., Mazzocco, M. M., Hanisch, L. B., \& Early, M. C. (2007). Cognitive characteristics of children with Mathematics Learning Disability (MLD) vary as a function of the cutoff criterion used to define MLD. Journal of Learning Disabilities, 40, 458-478.

Mussolin, C., De Volder, A., Grandin, C., Schlögel, X., Nassogne, M.-C., \& Noël, M.-P. (2010a). Neural correlates of symbolic number processing in developmental dyscalculia. Journal of Cognitive Neuroscience, 22, 860-874.

Mussolin, C., Meijas, P., \& Noël, M.-P. (2010b). Symbolic and nonsymbolic number comparison in children with and without dyscalculia. Cognition, 115, 10-25.

Norman, C. A., \& Zigmond, N. (1980). Characteristics of children labeled and served as learning disabled in school systems affiliated with child service demonstarition centers. Journal of Learning Disabilities, 13, 16-21.

Nuerk, H.-C., \& Willmes, K. (2005). On the magnitude representations of two digit numbers. Psychology Science, 47, 52-72.

Nuerk, H.-C., Weger, U., \& Willmes, K. (2001). Decade breaks in the mental number line? Putting the tens and units back in different bins. Cognition, 82, B25-B33. 
Nuerk, H.-C., Weger, U., \& Willmes, K. (2002). A unit-decade compatibility effect in German number words. Current Psychology Letters: Behavior, Brain \& Cognition, 2, 19-38.

Nuerk, H.-C., Kaufmann, L., Zoppoth, S., \& Willmes, K. (2004a). On the development of the mental number line: More or less or never holistic with increasing age. Developmental Psychology, 40, 1199-1211.

Nuerk, H.-C., Weger, U., \& Willmes, K. (2004b). On the perceptual generality of the unitdecade-compatibility effect. Experimental Psychology, 51, 72-79.

Nuerk, H.-C., Weger, U., \& Willmes, K. (2005). Language effects in magnitude comparison: Small, but not irrelevant. Brain and Language, 92, 262-277.

Nuerk, H.-C., Graf, M., \& Willmes, K. (2006). Grundlagen der Zahlenverarbeitung und des Rechnens. Sprache, Stimme, Gehör, 30, 147-153.

Nuerk, H.-C., Moeller, K., Klein, E., Willmes, K., \& Fischer, M. H. (2011). Extending the mental number line - A review of multi-digit number processing. Zeitschrift für Psychology/Journal of Psychology, 219, 3-22.

Opfer, J., \& Furlong, E. E. (2011). How numbers bias preschoolers spatial search. Journal of Cross-Cultural Psychology, 42(4), 682-695.

Opfer, J. E., \& Thompson, C. A. (2006). Even early representations of numerical magnitude are spatially organized: Evidence for a directional magnitude bias in pre-reading preschoolers. In R. Sun \& N. Miyaki (Eds.), Proceedings of the XXVIII annual conference of the Cognitive Science Society. Mahwah: Erlbaum.

Ostad, M. (1998). Developmental differences in solving simple arithmetic word problems and simple number-fact problems: A comparison of mathematically normal and mathematically disabled children. Mathematical Cognition, 4, 1-19.

Parsons, S., \& Bynner, J. (2005). Does numeracy matter more? London: National Research and Development Centre for Adult Literacy and Numeracy.

Pennington, B. F. (2006). From single to multiple deficit models of developmental disorders. Cognition, 101, 385-413.

Piazza, M., Facoetti, A., Trussardi, A. N., Bertelletti, I., Conte, S., Lucangeli, D., Dehaene, S., \& Zorzi, M. (2010). Developmental trajectory of number acuity reveals a severe impairment in developmental dyscalculia. Cognition, 116, 33-41.

Pinel, P., Le Clec'h, G., van de Moortele, P.-F., Naccache, L., LeBihan, D., \& Dehaene, S. (1999). Event-related fMRI analysis of the cerebral circuit for number comparison. Neuroreport, 10, $1473-1479$.

Pircher, C. (2007). Wirksamkeit eines multikomponentiellen Interventionsprogramms in Bezug auf die verbale Zahlenrepräsentation und die globale Beurteilung bei Kindern mit Rechenschwäche. Unpublished diploma's thesis, University of Salzburg, Salzburg.

Pixner, S., Moeller, K., Zuber, J., \& Nuerk, H.-C. (2009). Decomposed but parallel processing of two-digit numbers in 1st graders. The Open Psychology Journal, 2, 40-48.

Pixner, S., Moeller, K., Hermanova, V., Nuerk, H.-C., \& Kaufmann, L. (2011). Whorf reloaded: Language effects on nonverbal number processing in first grade - A trilingual study. Journal of Experimental Child Psychology, 108, 371-382.

Price, G. R., Holloway, I., Räsänen, P., Vesterinen, M., \& Ansari, D. (2007). Impaired parietal magnitude processing in developmental dyscalculia. Current Biology, 17, R1042.

Ramaa, S., \& Gowramma, I. P. (2002). A systematic procedure for identifying children with dyscalculia among primary school children in India. Dyslexia, 8, 67-85.

Räsänen, P., Salminen, J., Wilson, A. J., Aunio, P., \& Dehaene, S. (2009). Computer-assisted intervention for children with low numeracy skills. Cognitive Development, 24, 450-472.

Restle, F. (1970). Speed of adding and comparing numbers. Journal of Experimental Psychology, 83, 274-278.

Rickard, T. C. (2005). A revised identical elements model of arithmetic fact representation. Journal of Experimental Psychology: Learning, Memory, and Cognition, 31, 250-257.

Robinson, C. S., Menchetti, B. M., \& Torgesen, J. K. (2002). Toward a two-factor theory of one type mathematics disabilities. Learning Disabilities Research and Practice, 17, 81-89. 
Rotzer, S., Kucian, K., Martin, E., von Aster, M., Klaver, P., \& Loenneker, T. (2008). Optimized voxel-based morphometry in children with developmental dyscalculia. NeuroImage, 39, 417-422.

Rourke, B. P. (1993). Arithmetic disabilities, specific and otherwise - A neuropsychological perspective. Journal of Learning Disabilities, 26, 214-226.

Rourke, B. P., \& Conway, J. A. (1997). Disabilities of arithmetic and mathematical reasoning: Perspectives from neurology and neuropsychology. Journal of Learning Disabilities, 30, 34-46.

Rourke, B. P., \& Finlayson, M. A. (1978). Neuropsychological significance of variations in patterns of academic performance: Verbal and visual-spatial abilities. Journal of Abnormal Child Psychology, 6, 121-133.

Rousselle, L., \& Noël, M.-P. (2007). Basic numerical skills in children with mathematics learning disabilities: A comparison of symbolic vs. non-symbolic number magnitude processing. Cognition, 102, 361-395.

Rubinsten, O. (2009). Co-occurrence of developmental disorders: The case of developmental dyscalculia. Cognitive Development, 24, 362-370.

Rubinsten, O., \& Henik, A. (2005). Automatic activation of internal magnitudes: A study of developmental dyscalculia. Neuropsychology, 19, 641-648.

Rubinsten, O., \& Henik, A. (2009). Developmental dyscalculia: Heterogeneity may not mean different mechanisms. Trends in Cognitive Sciences, 13, 92-99.

Rubinsten, O., Bedard, A.-C., \& Tannock, R. (2008). Methylphenidate has differential effects on numerical abilities of children with ADHD with and without co-morbid mathematical difficulties. The Open Psychology Journal, 1, 11-17.

Rykhlevskaia, E., Uddin, L. Q., Kondos, L., \& Menon, V. (2009). Neuroanatomical correlates of developmental dyscalculia: Combined evidence from morphometry and tractography. Frontiers in Human Neuroscience, 3, 51.

Sarama, J., \& Clements, D. H. (2002). Building blocks for young children's mathematical development. Journal of Educational Computing Research, 27, 93-110.

Sarama, J., \& Clements, D. H. (2004). Building blocks for early childhood mathematics. Early Childhood Research Quarterly, 19, 181-189.

Shalev, R. S. (2004). Developmental dyscalculia. Journal of Child Neurology, 19, 765-771.

Shalev, R. S., \& Gross-Tsur, V. (2001). Developmental dyscalculia. Pediatric Neurology, 24, 337-342.

Shalev, R. S., Auerbach, J., Manor, O., \& Gross-Tsur, V. (2000). Developmental dyscalculia: Prevalence and prognosis. European Child \& Adolescent Psychiatry, 9, 558-564.

Shalev, R. S., Manor, O., \& Gross-Tsur, V. (2005). Developmental dyscalculia: A prospective sixyear follow-up. Developmental Medicine and Child Neurology, 47, 121-125.

Siegel, L. S., \& Ryan, E. B. (1989). The development of working memory in normally achieving and subtypes of learning disabled children. Child Development, 60, 973-980.

Siegler, R. S. (1988). Strategy choice procedures and the development of multiplication skill. Journal of Experimental Psychology. General, 117, 258-275.

Siegler, R. S., \& Booth, J. L. (2004). Development of numerical estimation in young children. Child Development, 75, 428-444.

Siegler, R. S., \& Ramani, G. B. (2009). Playing linear number board games - But not circular ones - Improves low-income preschoolers' numerical understanding. Journal of Educational Psychology, 101, 545-560.

Simon, O., Mangin, J.-F., Cohen, L., Le Bihan, D., \& Dehaene, S. (2002). Topographical layout of hand, eye, calculation, and language-related areas in the human parietal lobe. Neuron, 33, 475-487.

Slavin, R. (1983). When does cooperative learning increase student achievement? Psychological Bulletin, 94, 429-445.

Stern, W. (1911). Die differentielle Psychologie in ihren methodischen Grundlagen [The methodological fundamentals of differential psychology]. Leipzig: Barth. (Reprint 1994, Bern: Hans Huber.) 
Temple, C. M. (1989). Digit dyslexia: A category-specific disorder in developmental dyscalculia. Cognitive Neuropsychology, 6, 93-116.

Temple, C. M. (1991). Procedural dyscalculia and number fact dyscalculia: Double dissociation in developmental dyscalculia. Cognitive Neuropsychology, 8, 155-176.

Thurstone, L. L. (1938). Primary mental abilities. Psychometric Monographs 1, IX + 121.

Towse, J. N., \& Saxton, M. (1998). Mathematics across national boundaries: Cultural and linguistic perspectives on numerical competence. In C. Donlan (Ed.), The development of mathematics skills (pp. 129-150). Hove: Psychology Press.

U.S. Office of Education. (1977). Definition and criteria for defining students as learning disabled (Federal Register 42:250, p. 65083). Washington, DC: U.S. Government Printing Office.

van Galen, M. S., \& Reitsma, P. (2008). Developing access to number magnitude: A study of the SNARC effect in 7- to 9 year-olds. Journal of Experimental Child Psychology, 101, 99-113.

von Aster, M. (1994). Developmental dyscalculia in children: Review of the literature and clinical validation. Acta Paedopsychiatrica, 56, 169-178.

von Aster, M. G., Weinhold-Zulauf, M., \& Horn, R. (2006). ZAREKI-R - Neuropsychologische Testbatterie für Zahlenverarbeitung und Rechnen bei Kindern. Frankfurt: Harcourt.

von Aster, M., Schweiter, M., \& Weinhold-Zulauf, M. (2007). Rechenstörungen bei Kindern. Zeitschrift für Entwicklungspsychologie und Pädagogische Psychologie, 39, 85-96.

Webb, N. M. (1989). Peer interaction and learning in small groups. International Journal of Educational Research, 13, 21-39.

Weber, J. M., Marx, P., \& Schneider, W. (2002). Profitieren Legastheniker und allgemein leserechtschreibschwache Kinder in unterschiedlichem Ausmaß von einem Rechtschreibtraining. Psychologie in Erziehung und Unterricht, 49, 56-70.

Wechsler, D. (2003). Wechsler intelligence scale for children-Fourth edition. San Antonio: The Psychological Corporation.

Wechsler, D. (2008). Wechsler adult intelligence scale-Fourth edition. San Antonio: Pearson.

Wilson, A., \& Dehaene, S. (2007). Number sense and developmental dyscalculia: Human behavior, learning, and the developing brain. In D. Coch, G. Dawson, \& K. W. Fischer (Eds.), Human behavior, learning, and the developing brain: Atypical development (pp. 212-238). New York: Guilford.

Wilson, A. J., Dehaene, S., Pinel, P., Revkin, S., Cohen, L., \& Cohen, D. (2006a). Principles underlying the design of The Number Race, an adaptive computer game for remediation of dyscalculia. Behavioral and Brain Functions, 2, 19.

Wilson, A. J., Revkin, S., Cohen, D., Cohen, L., \& Dehaene, S. (2006b). An open trial assessment of The Number Race, an adaptive computer game for remediation of dyscalculia. Behavioral and Brain Functions, 2, 20.

Wood, G., Nuerk, H.-C., Moeller, K., Geppert, B., Schnitker, R., Weber, J., \& Willmes, K. (2008). All for one but not one for all: How multiple number representations are recruited in one numerical task. Brain Research, 1187, 154-166.

World Health Organization. (1992). International statistical classification of disease and related health problems, Tenth revision (ICD-10, Version 2007). Geneva: World Health Organization.

Wright, R. J., Martland, J., \& Stafford, A. K. (2000). Early numeracy. London: Paul Chapman Publications/Sage.

Wright, R. J., Martland, J., Stafford, A. K., \& Stanger, G. (2002). Teaching number: Advancing children's skills and strategies. London: Paul Chapman Publications/Sage.

Zhou, X., Chen, C., Chen, L., \& Dong, Q. (2008). Holistic or compositional representation oft two-digit numbers? Evidence from the distance, magnitude and SNARC effects in a number matching task. Cognition, 106, 1525-1536. 